\title{
A systematic study on the degradation products generated from artificially aged microplastics
}

\author{
Greta Biale ${ }^{1}$, Jacopo La Nasa ${ }^{1,2^{*}}$, Marco Mattonai ${ }^{1}$, Andrea Corti ${ }^{1}$, Virginia Vinciguerra ${ }^{1}$, Valter Castelvetro ${ }^{1,3}$, Fran- \\ cesca Modugno ${ }^{1,3}$ \\ 1 Department of Chemistry and Industrial Chemistry, University of Pisa, Pisa, Italy \\ 2 National Interuniversity Consortium of Materials Science and Technology, Florence, Italy \\ 3 CISUP - Center for the Integration of Scientific Instruments of the University of Pisa, University of Pisa, \\ Pisa, Italy \\ * Correspondence: jacopo.lanasa@for.unipi.it ; Tel.: +39050 0502219258
}

\begin{abstract}
Up to 13 million tons of plastic waste are estimated to enter the oceans every year. A generally accepted picture based on an increasing number of environmental studies suggests that the largest fraction of it consists or is rapidly degraded into microplastics (MPs). Most of the analytical studies focused on MPs are based on the detection and identification of the polymers. On the other hand, plastic debris in the environment undergo chemical (mainly photoxidative) and physical degradation processes leading not only to fragmentation but also to the formation of leachable, soluble and/or volatile degradation products that are released in the environment. The formation of such low molecular weight species is generally neglected in the studies on MPs even if these compounds, released in the environment from the plastics debris, may pose even higher risks for the environment and for the biota than the MPs particles themselves, risks that are far from being understood and assessed. In this study we performed the analysis of reference MPs - polymer micropowders obtained by grinding a set of five polymer types down to final size in the $857-509 \mu \mathrm{m}$ range, namely high- and low-density polyethylene (HDPE and LDPE, respectively), polystyrene (PS), polypropylene (PP), and polyethylene terephthalate (PET). The reference MPs were artificially aged in a SolarBox and their degradation products were analyzed to investigate their degradation processes. In particular, a systematic and thorough characterization of the aged (photo-oxidized) MPs and of their low molecular weight and/or highly oxidized fraction extractable in polar organic solvents was performed. For this purpose, the artificially aged MPs were subjected to selective extraction with organic solvent that are non-solvents for the virgin polymers, targeting selective recovery of the low molecular weight fractions generated during the artificial aging. Analysis of both the extractable fractions and the residues was carried out by a multi-technique approach combining evolved gas analysis-mass spectrometry (EGA-MS) and pyrolysis-gas chromatography-mass spectrometry (PyGC-MS). Up to $18 \mathrm{wt} \%$ of newly extractable, low molecular weight fraction was recovered from the photo-aged MPs, depending on the polymer type. The results highlight the need for more extensive studies about the potential harmfulness of the oxidation products (molecular and oxidized oligomeric species) that may leach out from plastic debris during their permanence in the environment.
\end{abstract}

Keywords: microplastics; artificial ageing; polymer degradation; artificial ageing; polyethylene; polypropylene; polystyrene; polyethylene terephthalate

\section{Introduction}

Due to the steadily increasing production of plastic materials since the second half of the 20th century, the mismanagement of a significant fraction of plastic waste resulted in massive plastic pollution becoming an environmental threat worldwide with potential risks for the biota and also for human health [1,2]. Therefore, the assessment of the amount, distribution and nature of the plastic debris in the ecosystems, and especially in 
the marine environment, is the focus of intense multidisciplinary research [3,4]. Currently, about 5-13 million tons of plastic waste are estimated to enter the ocean every year [5]. A generally accepted picture based on an increasing number of environmental studies suggests that the largest fraction of it consists of microplastics (MPs)[6]. While there is currently no scientific or regulatory agreement on the definition of a MPs size range, the commonly adopted $5 \mathrm{~mm}$ as the upper limit $[7,8]$ is being questioned as it relates to the ingestion by fish rather than to the physical and chemical properties. In fact, the latter are mainly related to the specific surface area and its rapid increase (roughly by a half of the third power) with the reduction of particle size; on the other hand, the specific surface area is likely to be more strictly related to the rate and extent of polymer degradation under environmental conditions, and thus with the interaction of MPs with the environment. A scientifically more appropriate size range of 1-1000 $\mu \mathrm{m}$ for MPs has recently been proposed [3,9]. The relevance of the size range of the MPs is exemplified by the observation that the higher the specific surface area, the faster the chemical degradation, mainly due to photo-oxidation processes, leading to the formation of leachable, soluble and/or volatile degradation products that need to be considered as an emerging source of environmental pollution deriving from MPs[10-13]. The most common analytical techniques used for the analysis of MPs are micro FTIR ( $\mu$-FTIR), and micro Raman spectroscopy[14,15], both providing information that does not allow to clearly highlight the differences between the surface and bulk composition and to pinpoint the presence and relative amount of highly degraded fractions and of degradation products that are likely to affect the most the chemical behavior of MPs. On the other hand, in the last years thermoanalytical approaches have emerged as powerful tools for studying MPs [16-18], also in routine analysis of contaminated environmental samples [19]. Among them, analytical pyrolysis [20-22] allows the sensitive and accurate characterization of polymers and polymer mixtures through their pyrolytic profiles. The systematic study presented here is based on a combination of analytical pyrolysis approaches and mass spectrometry detection to evaluate the effects of simulated environmental photo-oxidative degradation processes in five different reference MPs. We describe the parallel characterization of the bulk chemical modifications, and of the low-molecular-weight, leachable or soluble organic fraction resulting from the polymer degradation. Investigating the relation between the modifications of the different polymers under simulated environmental aging, and the nature and amount of low molecular weight species resulting from the polymer degradation - as evaluated by their enhanced solubility in polar organic solvents - is fundamental to assess their possible role as emerging environmental pollutants as they may leach out of the MPs, being thus potentially harmful for living organisms. The reference polymers were selected among those most commonly found in the form of MPs in the environment as a result of plastic waste dispersion, namely: polypropylene (PP), polystyrene (PS), polyethylene terephthalate (PET), low-density polyethylene (LDPE) and high-density polyethylene (HDPE). The virgin polymers in the form of micropowders (average particle size in the 857-509 $\mu \mathrm{m}$ range) were aged in a Solar-Box for four weeks. Samples were periodically collected and analyzed by means of evolved gas analysis-mass spectrometry (EGAMS) and the results were compared with those obtained for the unaged polymers in order to study the thermal degradation behavior specific for each polymer during photo-aging. The unaged and the 4 weeks aged polymer samples were also characterized by means of pyrolysis-gas chromatography-mass spectrometry (Py-GC-MS) to detect and identify the produced alteration and degradation products. Finally, all samples were subjected to solvent extraction in either methanol (for PS) or refluxing dichloromethane (for PP, PET, LDPE and HDPE), that are non-solvents for the virgin polymers, to selectively extract the low molecular weight fractions generated by chain scissions as a result of extensive degradation. The solvent extracts were then analyzed by size exclusion chromatography (SEC) and Py-GC-MS using hexamethyldisilazane (HMDS) as derivatizing agent to detect the compounds characterized by high polarity and low-volatility like the ones resulting from photo-oxidative processes entailing radical oxygen inclusion reactions. The 
insoluble polymer fractions were also analyzed by means of Py-GC-MS to evaluate their chemical modifications and compare them with those of the most highly degraded, solvent extractable fractions.

\section{Materials and Methods}

\subsection{Chemicals}

Dichloromethane (DCM, HPLC grade, Sigma-Aldrich) and methanol (MeOH, HPLC grade, Sigma-Aldrich) were used as solvents in the extractions. Hexamethyldisilazane (HMDS $\geq 99 \%$, Sigma-Aldrich) was used as derivatizing agent for the in situ thermally assisted silylation of the pyrolysis products bearing carboxylic and hydroxyl groups in the Py-GC-MS analysis of the polymer extracts.

\subsection{Reference Polymers}

Micronized polypropylene (PP), polystyrene (PS), polyethylene terephthalate (PET), lowdensity polyethylene (LDPE) and high-density polyethylene (HDPE), with average particle size in the 857-509 $\mu \mathrm{m}$ range depending on the polymer as reported elsewhere [23,24], were kind gifts from Poliplast S.p.A (Casnigo, Italy).

\subsection{Artificial aging and extraction}

PP, PS, PET, LDPE and HDPE micropowders were artificially aged for four weeks using a Solar-Box system (CO.FO.ME.GRA. Srl, Milan, Italy) equipped with a Xenon-arc lamp and outdoor filter. The conditions for the aging were: temperature $40{ }^{\circ} \mathrm{C}$, irradiance 750 $\mathrm{W} / \mathrm{m} 2$, relative humidity around $60 \%$. Aliquots (ca. $200 \mathrm{mg}$ ) of each polymer were collected before $(0 \mathrm{w})$ and after $1(1 \mathrm{w}), 2(2 \mathrm{w}), 3(3 \mathrm{w})$, and $4(4 \mathrm{w})$ weeks of artificial aging and stored in sealed glass vials at $-20^{\circ} \mathrm{C}$ until analysis [23,24]. About $150 \mathrm{mg}$ of each unaged and aged polymer sample was extracted for 6 hours with $30 \mathrm{ml}$ either MeOH (for PS) or DCM (all other polymers) in a Soxhlet apparatus, collecting both the residues and the extractable fractions for the subsequent characterizations. $\mathrm{MeOH}$ and DCM, that act as nonsolvents for the virgin polymers, were chosen to selectively extract the degraded, low molecular weight fractions. The extracted fractions were dried in a rotary evaporator until constant weight and then stored in glass vials before the Py-GC-MS and SEC analyses. Procedural blanks (DCM and $\mathrm{MeOH}$ ) were also prepared and analyzed along with the polymer extracts.

\subsection{Analytical methods and instrumentation}

\subsubsection{Evolved Gas Analysis-Mass Spectrometry (EGA-MS)}

The EGA-MS analyses of unaged and artificially aged bulk polymers were performed with an EGA/PY-3030D micro-furnace pyrolyzer (Frontier Laboratories Ltd., Japan) coupled to a 6890 gas chromatograph and a 5973 mass spectrometric detector (Agilent Technologies, USA). The experimental conditions were the following: temperature ramp for the furnace from $50^{\circ} \mathrm{C}$ to $700{ }^{\circ} \mathrm{C}$ at $10^{\circ} \mathrm{C} / \mathrm{min}$; interface between the pyrolysis furnace and the GC-MS system set at a temperature $100{ }^{\circ} \mathrm{C}$ higher than that of the furnace, but limited to a maximum of $300{ }^{\circ} \mathrm{C}$; GC injector operated in split mode (20:1 ratio) at $280{ }^{\circ} \mathrm{C}[25,26]$. The evolved pyrolysis products were directly sent to the mass spectrometer using a UADTM-2.5N deactivated stainless-steel capillary tube $(3 \mathrm{~m} \times 0.15 \mathrm{~mm}$, Frontier Laboratories Ltd., Japan) held at $300{ }^{\circ} \mathrm{C}$, and using helium $(1 \mathrm{~mL} / \mathrm{min})$ as the carrier gas. The temperature of the transfer line to the mass spectrometer was $280^{\circ} \mathrm{C}$. The mass spectrometer was operated in EI positive mode $(70 \mathrm{eV}, \mathrm{m} / \mathrm{z}$ range $15-700)$. The temperatures of the ion source and quadrupole analyzer were $230{ }^{\circ} \mathrm{C}$ and $150{ }^{\circ} \mathrm{C}$, respectively. Each $100-250$ $\mu \mathrm{g}$ sample was directly weighed in the deactivated stainless-steel pyrolysis cup with an XS3DU microanalytical scale (Mettler-Toledo, USA) with seven digits and a precision of $1 \mu \mathrm{g}$. 


\subsubsection{Pyrolysis-Gas Chromatography-Mass Spectrometry (Py-GC-MS)}

Analyses of unaged and artificially aged bulk polymers, their extracts, and the corresponding extraction residues (insoluble fractions) were performed using a multi-shot pyrolyzer EGA/PY-3030D (Frontier Lab) coupled with a $6890 \mathrm{~N}$ gas chromatography system with a split/splitless injection port and combined with a 5973 mass selective single quadrupole mass spectrometer (Agilent Technologies). The samples (50-100 $\mu \mathrm{g})$ were placed in deactivated stainless-steel sample cups. Pyrolysis conditions were optimized as follows: pyrolysis temperatures were selected based on the samples analyzed [25-27]; interface 280 ${ }^{\circ} \mathrm{C}$; GC injector temperature $280^{\circ} \mathrm{C}$; GC injection operated in split mode with an optimized 10:1 split ratio. The chromatographic separation of the pyrolysis products was performed on a fused silica capillary column HP-5MS (5\% diphenyl-95\% dimethyl-polysiloxane, 30 $\mathrm{m} \times 0.25 \mathrm{~mm}$ i.d., $0.25 \mu \mathrm{m}$ film thickness, J\&W Scientific, Agilent Technologies) preceded by a deactivated fused silica pre-column $(2 \mathrm{~m} \times 0.32 \mathrm{~mm}$ i.d.). The chromatographic conditions were: $40{ }^{\circ} \mathrm{C}$ for $5 \mathrm{~min}, 10{ }^{\circ} \mathrm{C} / \mathrm{min}$ to $310{ }^{\circ} \mathrm{C}$ for $20 \mathrm{~min}$, carrier gas (He, 99.9995\%) flow $1.2 \mathrm{~mL} / \mathrm{min}$. MS parameters: electron impact ionization (EI, $70 \mathrm{eV}$ ) in positive mode; ion source temperature $230{ }^{\circ} \mathrm{C}$; scan range $35-700 \mathrm{~m} / \mathrm{z}$; interface temperature $280^{\circ} \mathrm{C}$. Perfluorotributylamine (PFTBA) was used for mass spectrometer tuning. MSD ChemStation (Agilent Technologies) software was used for data analysis and peak assignment was based on a mass spectra libraries (NIST 8, score higher than 80\%) and literature data [20]. For the analysis of the polymer samples and the polymer residues (after extraction), the pyrolysis furnace was set at $600{ }^{\circ} \mathrm{C}$ and samples ranging from 50 to $100 \mu \mathrm{g}$ were directly weighed in the deactivated stainless-steel pyrolysis cup with an XS3DU microanalytical scale (Mettler-Toledo, USA) with seven digits and a precision of $1 \mu \mathrm{g}$. For the analysis of the extracted fraction of the reference polymer samples, $1 \mathrm{~mL}$ of DCM was added to each vial containing the polymer dried extracts; regarding PS dried extract, $1 \mathrm{~mL}$ of methanol was used, since it is the solvent used for its extraction. Then, different volumes of the extracts $(20-340 \mu \mathrm{L})$ were directly dried in the pyrolysis cup and then weighed with an XS3DU microanalytical scale in order to obtain about $100 \mu \mathrm{g}$ of sample. $4 \mu \mathrm{L}$ of HMDS were added in the pyrolysis cup as derivatizing agent in order to detect polar and lowvolatility compounds. Pyrolysis temperature was set at $550{ }^{\circ} \mathrm{C}$. HMDS was used in the cleaning pre-treatment of the Py-GC-MS system.

\subsubsection{Size-exclusion Chromatography (SEC)}

Size exclusion chromatography (SEC) analysis of the extracts of unaged and aged polymers was performed with a Jasco (Jasco Europe srl, Italy) instrument comprising a PU2080 Plus four-channel pump with degasser, two in series PL gel MIXED-E Mesopore (Polymer Laboratories) columns placed in a Jasco CO-2063 column oven thermostated at $30{ }^{\circ} \mathrm{C}$, a Jasco RI 2031 Plus refractive index detector, and a Jasco UV-2077 Plus multi-channel UV 120 spectrometer; the ChromNav Jasco software was used for data acquisition and analysis. The eluent was trichloromethane (HPLC grade Sigma-Aldrich) at $1 \mathrm{~mL} / \mathrm{min}$ flow rate

\section{Results and discussion}

The micropowders of all reference polymers were artificially aged 4 weeks under conditions roughly corresponding to a 6-month exposure at the latitude of Tuscany region, in central Italy. The pristine (unaged virgin polymers) and the irradiated samples collected after each subsequent 1-week period of artificial aging were analyzed by means of EGA-MS, and Py-GC-MS to gain information about the extent of the photo-oxidative degradation and the type of chemical damage induced by the photo-aging. Pristine and artificially aged polymers were also extracted with solvents suitable for separating the low molecular weight photo-oxidized fragments from the insoluble bulk polymer. Finally, the two fractions obtained upon solvent extraction of each sample (organic extract containing the soluble degradation products, and residue containing the insoluble polymers) 
were characterized by Py-GC-MS and, in the case of the extracts containing the soluble fraction produced upon aging, also by SEC. The overall procedure is schematically summarized in Figure 1. The extraction yields and their variation during artificial aging are reported in Figure 2. A higher rate of degradation, as simply weighed by the increase of the fraction of extractable material upon aging, was observed for the PP, LDPE, and PS, all of which bearing a tertiary $\mathrm{C}-\mathrm{H}$ bond that is more easily attacked by free radical species directly or indirectly generated by photo-irradiation. However, while the extractable fraction increases about linearly with the irradiation time for the three polyolefins (i.e., including HDPE), a tendency resembling an exponential growth or indicating some initial inhibition effect can be observed for PS, possibly as a result of some free radical scavenging effect associated with either the presence of the monosubstituted phenyl ring, or the higher glass transition temperature (Tg) of PS, or both.

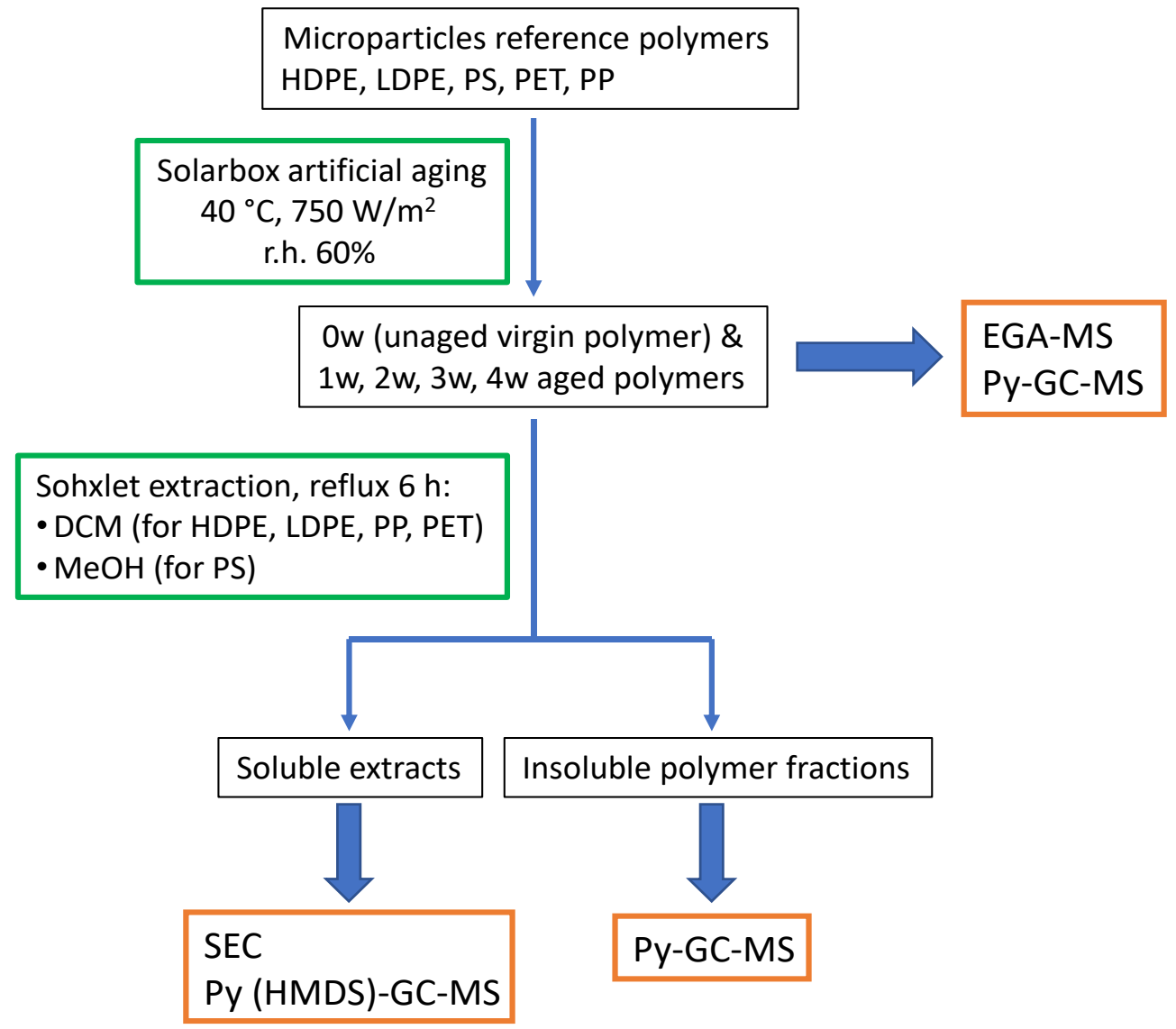

Figure 1 Flowsheet of the overall procedure for the investigation of the polymer degradation products generated upon accelerated photo-oxidative aging. 


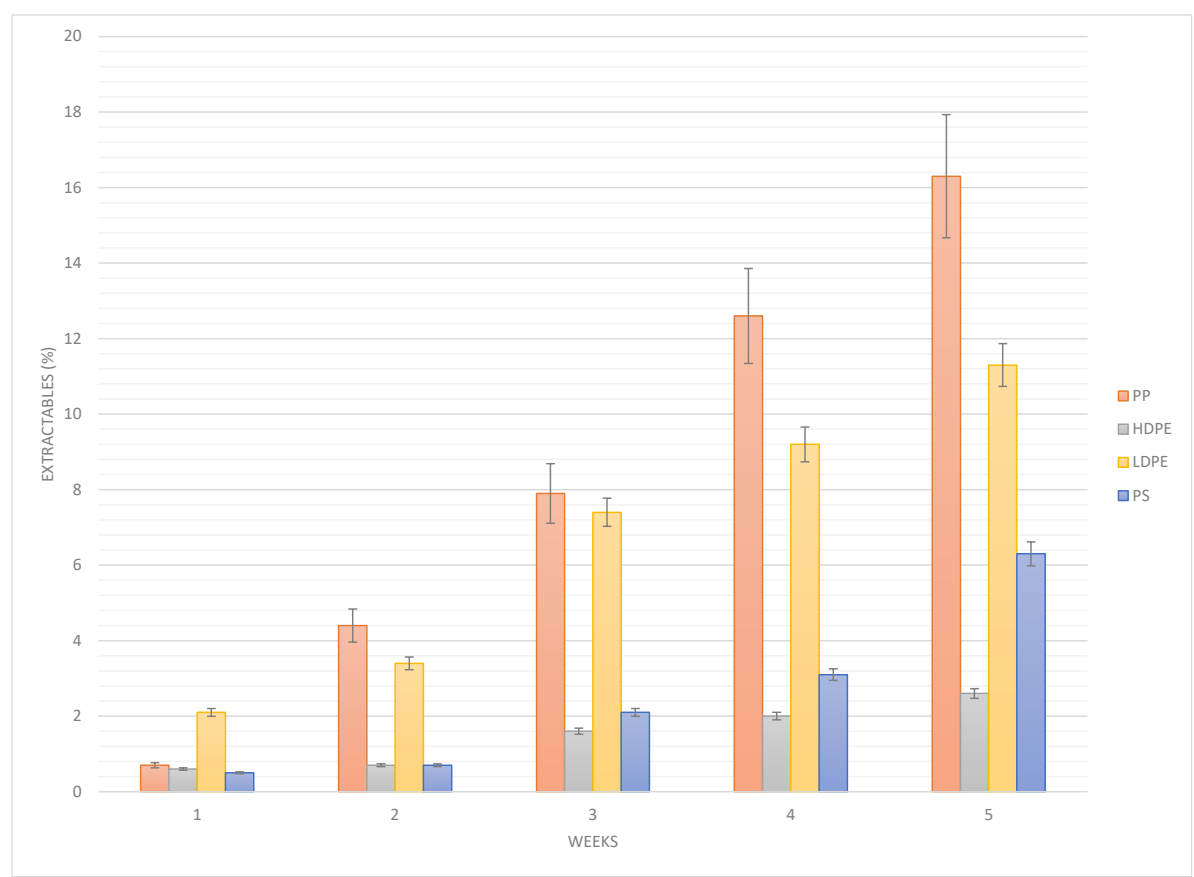

Figure 2 Extractable fractions ( $\mathrm{w} \%$ ) for each reference polymer sample upon artificial aging ( $10 \%$ error bars).

\subsection{EGA-MS and Py-GC-MS analysis of polymers during artificial aging}

EGA analyses were performed on the $0 \mathrm{w}$ (unaged), $1 \mathrm{w}, 3 \mathrm{w}$, and $4 \mathrm{w}$ polymer samples to evaluate changes in the thermal degradation temperature profiles. The $0 \mathrm{w}$ and $4 \mathrm{w}$ samples, representing the initial and final situation, were also analyzed by Py-GC-MS. The results are reported and discussed in the following paragraphs, separately for each polymer type.

\subsubsection{Polypropylene}

The EGA profiles for virgin and aged PP are shown in Figure 3, each curve being the average of five replicates.

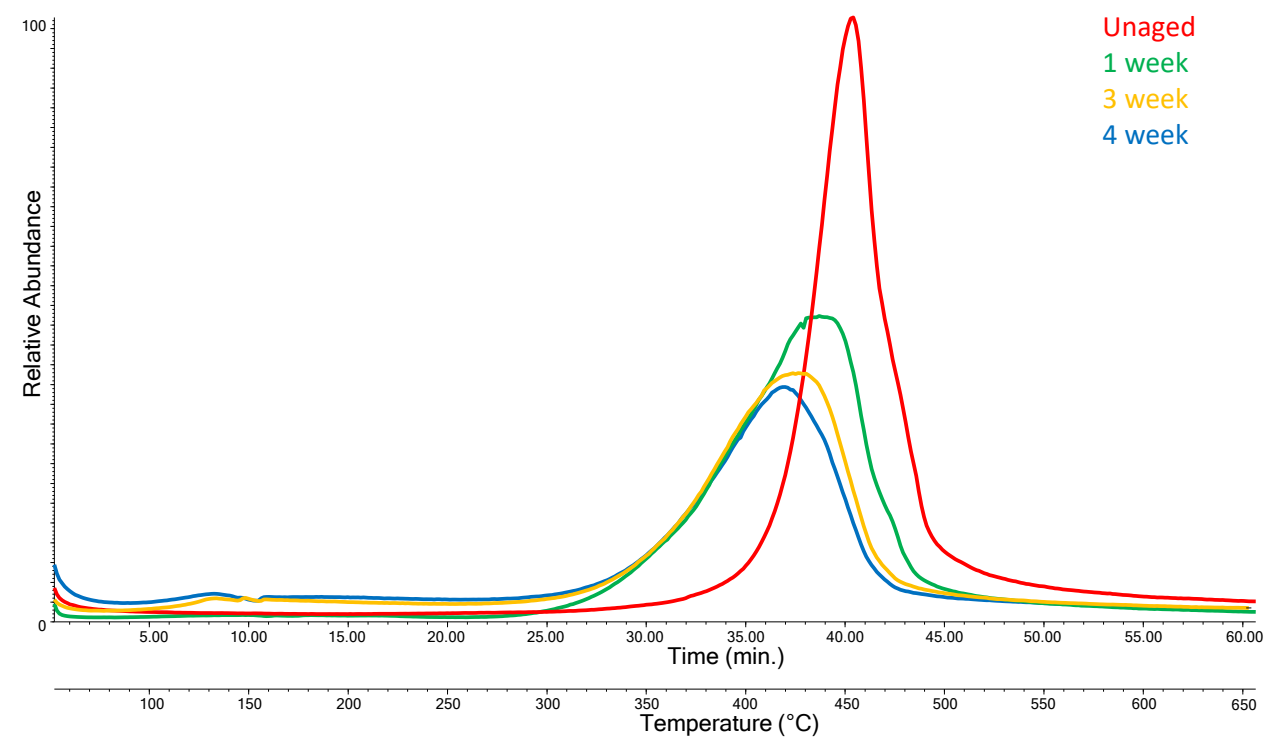

Figure 3 EGA profiles of PP after different artificial aging times: PP- $0 w$ (red), PP-1w (green), PP-3w (yellow), and PP-4w (blue) accelerated aging. 
Based on a statistical evaluation of the five replicated analyses (t-test, 95\%), a difference higher than $5,2{ }^{\circ} \mathrm{C}$ in the thermal degradation temperature, $\mathrm{T}_{\mathrm{D}}$, taken as the temperature corresponding to the maximum of the EGA peak, can be considered as significant. The EGA profiles show a change in the thermal degradation profile of PP upon aging. In particular, photodegradation induces a progressive decrease of $\mathrm{T}_{\mathrm{D}}$ and a broadening of the thermal degradation peak (Table 1), with a $\mathrm{T}_{\mathrm{D}}$ drop of $35^{\circ} \mathrm{C}$ from $\mathrm{T}_{\mathrm{D}}=453^{\circ} \mathrm{C}$ for the unaged PP-0w down to $418^{\circ} \mathrm{C}$ for PP- $4 \mathrm{w}$. An even more consistent drop is observed for the onset temperature of the thermal degradation peak: from $421^{\circ} \mathrm{C}$ for the unaged PP- $0 \mathrm{w}$ down to $350{ }^{\circ} \mathrm{C}$ for PP- $4 \mathrm{w}$.

Table 1 Degradation temperature ranges and peak maxima (TD max) obtained from the EGA-MS profiles of the PP samples; (a) Onset and offset temperatures determined at the intersection of the baseline with the tangent at the inflection point of the upward and downward slope of the EGA peak, respectively.

\begin{tabular}{lll}
\hline Polypropylene & Degradation temperature range $\left({ }^{\circ} \mathbf{C}\right)^{(a)}$ & TD $\max \left({ }^{\circ} \mathbf{C}\right)$ \\
\hline PP-0w & $421-480$ & 453 \\
PP-1w & $350-484$ & 437 \\
PP-3w & $350-463$ & 424 \\
PP-4w & $350-458$ & 418 \\
\hline
\end{tabular}

PP is known to be very susceptible to chain scission reactions as a result of photo-induced degradation processes, its reactivity being higher than that of both HDPE and LDPE, due to the higher concentration of tertiary $\mathrm{C}-\mathrm{H}$ bonds. The latter are more susceptible to free radical attack typically resulting in hydrogen extraction, followed by a series of reactions eventually leading to random chain scissions and consequent rapid reduction of the molecular weight $[10,28,29]$. This behavior is in full agreement with the evolution of the EGA profiles during artificial aging as observed in our experiments, featuring the above discussed progressive TD lowering and peak broadening, as a result of the growing concentration of chain scission products and of reactive oxidized and unsaturated groups, less thermally stable than saturated hydrocarbon structures. As expected, such structural changes did not induce any significant change in the EGA-MS mass spectra of the polymer thermal degradation products (the average mass spectra is obtained averaging the EGAMS mass spectra in the temperature range corresponding to the peak, and is reported in Figure S.1 in the Supplementary Materials). The most abundant ion fragments in the average EGA mass spectrum of $\mathrm{PP}-0 \mathrm{w}$ (spectra collected in the temperature range from 421 ${ }^{\circ} \mathrm{C}$ to $480{ }^{\circ} \mathrm{C}$ ) are $\mathrm{m} / \mathrm{z} 43,69,83,97,111,125,153$, corresponding to PP oligomers with different chain lengths (Table 2) [20]. The Py-GC-MS chromatogram of PP-0w is shown in Figure 4, while its peak assignments are listed in Table 2 . The most abundant pyrolysis products are 2,4-dimethyl-1-heptene $\left(n^{\circ} 6\right)$, 2,4,6-trimethyl-1-nonene $\left(n^{\circ} 12,13\right), 2,4,6,8$ tetramethyl-1-undecene $\left(n^{\circ} 16,17,18\right)$ along with other polypropylene oligomers of increasing chain length $\left(\mathrm{n}^{\circ} 19-44\right)$, in agreement with the well-known pyrolytic behavior of $\mathrm{PP}$ involving random $\mathrm{C}-\mathrm{C}$ scissions followed by intramolecular $\mathrm{H}$ transfer yielding alkanes and 1-alkenes [20,30]. The pyrolysis profiles of PP- $0 \mathrm{w}$ and PP-4w are very similar. In particular, no pyrolysis products indicative of the occurrence of photoaging-related polymer degradation could be detected. In fact, the EGA profile did highlight the occurrence and progress of polymer degradation processes during the aging experiment; on the other hand, the missed detection of molecular fragments that could be associated with the increasing fraction of oxidized products resulting from the photo-oxidative degradation may be explained by their low concentration in the bulk polymer, and by the poor effectiveness of the GC-MS separation and detection section in a conventional Py-GC-MS apparatus when oxidation products are involved, unless in situ thermally assisted 
derivatization of the carboxylic/hydroxyl functions is applied prior to the analysis. In order to detect the presence of degradation products generated by artificial aging and to achieve an exhaustive characterization, solvent extraction was applied, and the extractable fractions of reference polymers before and after artificial aging were analyzed by means of Py-GC-MS using a derivatization agent.

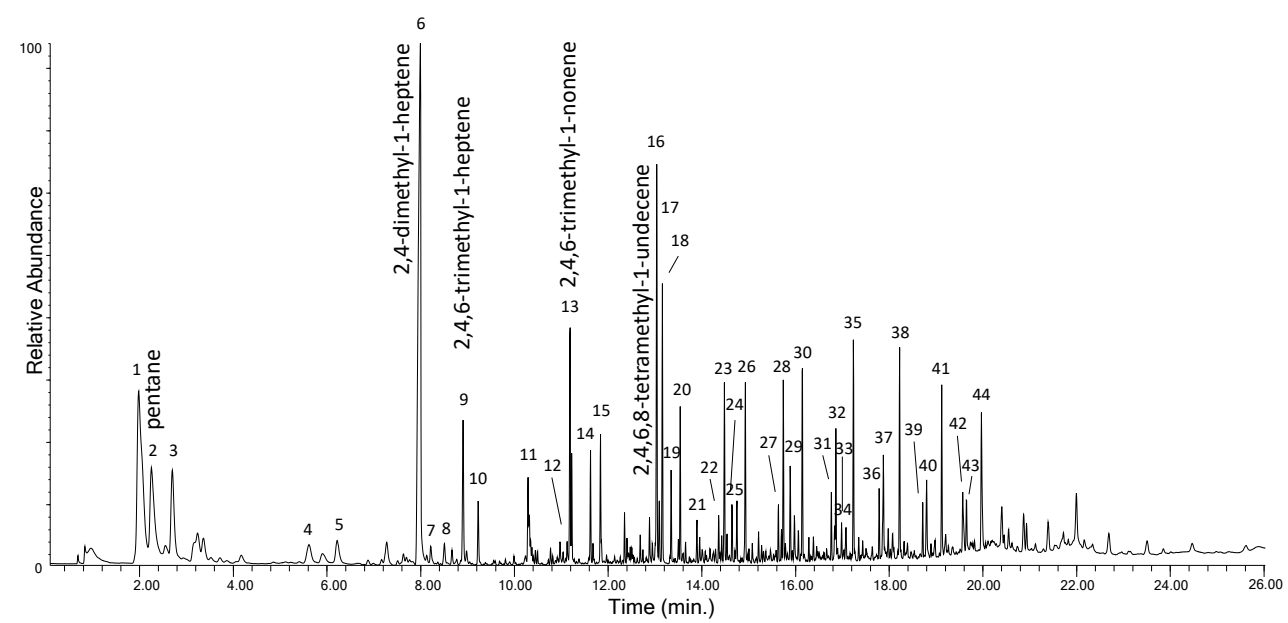

Figure 4 Chromatogram obtained in the Py-GC-MS analysis of the unaged PP (PP-0w). Peak identification is reported in Table 2.

Table 2 Identification of peaks in the chromatogram obtained in the Py-GC-MS analysis of PP- $0 \mathrm{w}$ (Figure 4) [20]. $\mathrm{M}^{+}$refers to the molecular ion.

\begin{tabular}{|c|c|c|c|}
\hline \# & $\operatorname{tr}(\min )$ & Peak identification & Main ions $(m / z)$ \\
\hline 1 & 1.9 & propene & $42\left(\mathrm{M}^{+}\right), 41,39$ \\
\hline 2 & 2.2 & pentane & $72\left(\mathrm{M}^{+}\right), 57,43$ \\
\hline 3 & 2.7 & 2,methyl-1-pentene & $84\left(\mathrm{M}^{+}\right), 69,56,41$ \\
\hline 4 & 5.6 & 4-methyl-2-heptene & $112\left(\mathrm{M}^{+}\right), 69,55,41$ \\
\hline 5 & 6.2 & 2-methyl-1,5-hexadiene & $95,81,67,55,39$ \\
\hline 6 & 8.0 & 2,4-dimethyl-1-heptene & $126\left(\mathrm{M}^{+}\right), 83,70,55,43$ \\
\hline 7 & 8.2 & 1,3,5-trimethylcyclohexane (isomer) & $126,111,69,55,41$ \\
\hline 8 & 8.5 & 2,4-dimethyl-1,6-heptadiene & $124\left(\mathrm{M}^{+}\right), 109,81,67,55,41$ \\
\hline 9 & 8.9 & 2,4,6-trimethyl-1-heptene & $140\left(\mathrm{M}^{+}\right), 83,69,55,43$ \\
\hline 10 & 9.2 & 2,4,6-trimethyl-1,6-heptadiene & $138\left(\mathrm{M}^{+}\right), 123,109,95,82,67,55,41$ \\
\hline 11 & 10.3 & 4,6-dimethyl-2-nonene & $154\left(\mathrm{M}^{+}\right), 111,85,69,55,41$ \\
\hline 12 & 11.1 & 2,4,6-trimethyl-1-nonene & $168\left(\mathrm{M}^{+}\right), 125,111,83,69,57,43$ \\
\hline 13 & 11.2 & 2,4,6-trimethyl-1-nonene & $168\left(\mathrm{M}^{+}\right), 125,111,83,69,57,43$ \\
\hline 14 & 11.6 & 2,4,6,8-tetramethyl-1-nonene & $182\left(\mathrm{M}^{+}\right), 125,111,83,69,57,43$ \\
\hline 15 & 11.8 & 2,4,6,8-tetramethyl-1,8-nonadiene & $180\left(\mathrm{M}^{+}\right), 123,109,96,83,69,55,41$ \\
\hline 16 & 13.0 & 2,4,6,8-tetramethyl-1-undecene & $210\left(\mathrm{M}^{+}\right), 154,111,83,69,55,43$ \\
\hline 17 & 13.1 & 2,4,6,8-tetramethyl-1-undecene & $210\left(\mathrm{M}^{+}\right), 154,111,85,69,55,43$ \\
\hline 18 & 13.2 & 2,4,6,8-tetramethyl-1-undecene & $210\left(\mathrm{M}^{+}\right), 154,111,85,69,55,44$ \\
\hline 19 & 13.3 & 2,4,6,8,10-pentamethyl-1-undecene & $224\left(\mathrm{M}^{+}\right), 125,111,97,83,69,57,43$ \\
\hline 20 & 13.6 & 2,4,6,8,10-pentamethyl-1,10-undecadiene & $222\left(\mathrm{M}^{+}\right), 123,109,95,83,69,55,41$ \\
\hline 21 & 13.9 & unknown & $153,125,111,97,85,69,57,43$ \\
\hline 22 & 14.3 & 2,4,6,8,10-pentamethyl-1,12-tridecadiene & $250\left(\mathrm{M}^{+}\right), 123,109,95,83,69,55,41$ \\
\hline
\end{tabular}




\begin{tabular}{|c|c|c|}
\hline 2314.5 & 2,4,6,8,10-pentamethyl-1-tridecene & $252\left(\mathrm{M}^{+}\right), 125,111,97,83,69,57,43$ \\
\hline 14.6 & unknown & $196,125,111,97,83,69,57,43$ \\
\hline 14.7 & unknown & $153,125,111,97,83,69,57,43$ \\
\hline 14.9 & 2,4,6,8,10,12-hexamethyl-1,12-tridecadiene & $264\left(\mathrm{M}^{+}\right), 123,109,95,83,69,55,41$ \\
\hline 15.6 & 2,4,6,8,10,12-hexamethyl-1,14-pentadecadiene & $292\left(\mathrm{M}^{+}\right), 137,109,97,83,69,55,41$ \\
\hline 15.7 & 2,4,6,8,10,12-hexamethyl-1-pentadecene & $294\left(\mathrm{M}^{+}\right), 139,111,97,83,69,57,43$ \\
\hline 15.9 & unknown & $294,139,125,111,97,83,69,57,43$ \\
\hline 16.1 & 2,4,6,8,10,12,14-heptamethyl-1,14-pentadecadiene & $306\left(\mathrm{M}^{+}\right), 123,109,97,83,69,55,41$ \\
\hline 16.8 & 2,4,6,8,10,12,14-heptamethyl-1,16-heptadecadiene & $334\left(\mathrm{M}^{+}\right), 123,109,97,83,69,55,41$ \\
\hline 16.9 & 2,4,6,8,10,12,14-heptamethyl-1-heptadecene & $336\left(\mathrm{M}^{+}\right), 125,111,97,83,69,57,43$ \\
\hline 17.0 & unknown & $153,125,111,97,83,69,57,43$ \\
\hline 17.1 & unknown & $153,125,111,97,83,69,57,43$ \\
\hline 17.2 & 2,4,6,8,10,12,14,16-octamethyl-1,16-heptadecadiene & $348\left(\mathrm{M}^{+}\right), 123,109,97,83,69,55,41$ \\
\hline 17.8 & 2,4,6,8,10,12,14,16-octamethyl-1,18-nonadecadiene & $376\left(\mathrm{M}^{+}\right), 125,109,97,83,69,55,41$ \\
\hline 17.9 & 2,4,6,8,10,12,14,16-octamethyl-1-nonadecene & $378\left(\mathrm{M}^{+}\right), 125,111,97,83,69,57,43$ \\
\hline 18.2 & 2,4,6,8,10,12,14,16,18-nonamethyl-1,18-nonadecadiene & $390\left(\mathrm{M}^{+}\right) 125,109,97,83,69,55,41$ \\
\hline 18.7 & 2,4,6,8,10,12,14,16,18-nonamethyl-1,20-henicosadiene & $418\left(\mathrm{M}^{+}\right), 125,111,97,83,69,55,41$ \\
\hline 18.8 & 2,4,6,8,10,12,14,16,18-nonamethyl-1-henicosene & $420\left(\mathrm{M}^{+}\right), 125,111,97,83,69,57,43$ \\
\hline 19.1 & 2,4,6,8,10,12,14,16,18,20-decamethyl-1,20-henicosadiene & $432\left(\mathrm{M}^{+}\right), 125,109,97,83,69,55,43$ \\
\hline 19.6 & 2,4,6,8,10,12,14,16,18,20-decamethyl-1,22-tricosadiene & $460\left(\mathrm{M}^{+}\right), 125,111,97,83,69,55,41$ \\
\hline 19.7 & 2,4,6,8,10,12,14,16,18,20-decamethyl-1-tricosene & $153,139,125,111,97,83,69,57,43$ \\
\hline 20.0 & 2,4,6,8,10,12,14,16,18,20,22-undecamethyl-1,22-tricosadiene & $474\left(\mathrm{M}^{+}\right), 125,111,97,83,69,55,43$ \\
\hline
\end{tabular}

\subsubsection{Polystyrene (PS)}

All the EGA-MS curves feature a single peak in the temperature interval $350-450{ }^{\circ} \mathrm{C}$ (Figure S.2 in Supplementary Materials), with a maximum TD at about $406{ }^{\circ} \mathrm{C}$. A slight decrease of the onset temperature $\left(\Delta \mathrm{T}=8^{\circ} \mathrm{C}\right)$ observed in the EGA profile of the PS- $3 \mathrm{w}$ and PS- $4 \mathrm{w}$ samples can be associated to the formation of photo-oxidized products, although in a comparatively smaller amounts with respect to the case of PP as seen before. In the average mass spectrum of PS $\left(350-450{ }^{\circ} \mathrm{C}\right.$, Figure S.3 in Supplementary Materials), the most abundant ions are fragments with $\mathrm{m} / \mathrm{z} 51,65,78,91,104,117,207$, corresponding to the ions in the mass spectra of the well-known pyrolysis products of the polymer (toluene, styrene, styrene dimer and styrene trimer, Table 3) [20]. By comparing the mass spectra of the four samples, no significant differences in the relative abundance of the main ions are detected. In the Py-GC-MS chromatogram of PS-0w (Figure 5 and Table 3 ) the most abundant pyrolysis products are styrene $\left(n^{\circ} 2\right), \alpha$-methylstyrene ( $\left.n^{\circ} 5\right), 3$-butene-1,3-diyldibenzene (styrene dimer, $\mathrm{n}^{\circ} 13$ ) and 5-hexene-1,3,5-triyltribenzene (styrene trimer, $\mathrm{n}^{\circ} 17$ ). This is in agreement with the typical thermal degradation processes of PS, mainly characterized by depolymerization pathways.

The pyrolysis profile of PS- $4 \mathrm{w}$ and PS-0w are very similar. This lack of differences between the two pyrolysis profiles can be explained by the tendency of PS to produce hydroquinonic structures as result of photo-oxidation, which are known for their antioxidant and free radical scavenging properties and are thus likely to generate a chemically altered surface layer protecting the bulk polymer from further photo-oxidative degradation[28,31].

The yellowing observed in the PS- $4 \mathrm{w}$ sample is a direct consequence of such surface-limited formation of oxidized and possibly conjugated aromatic structures, which do not 
significantly affect the EGA-MS curves and the pyrolysis profiles of the aged PS because degradation only involves a small fraction of the overall polymer mass.

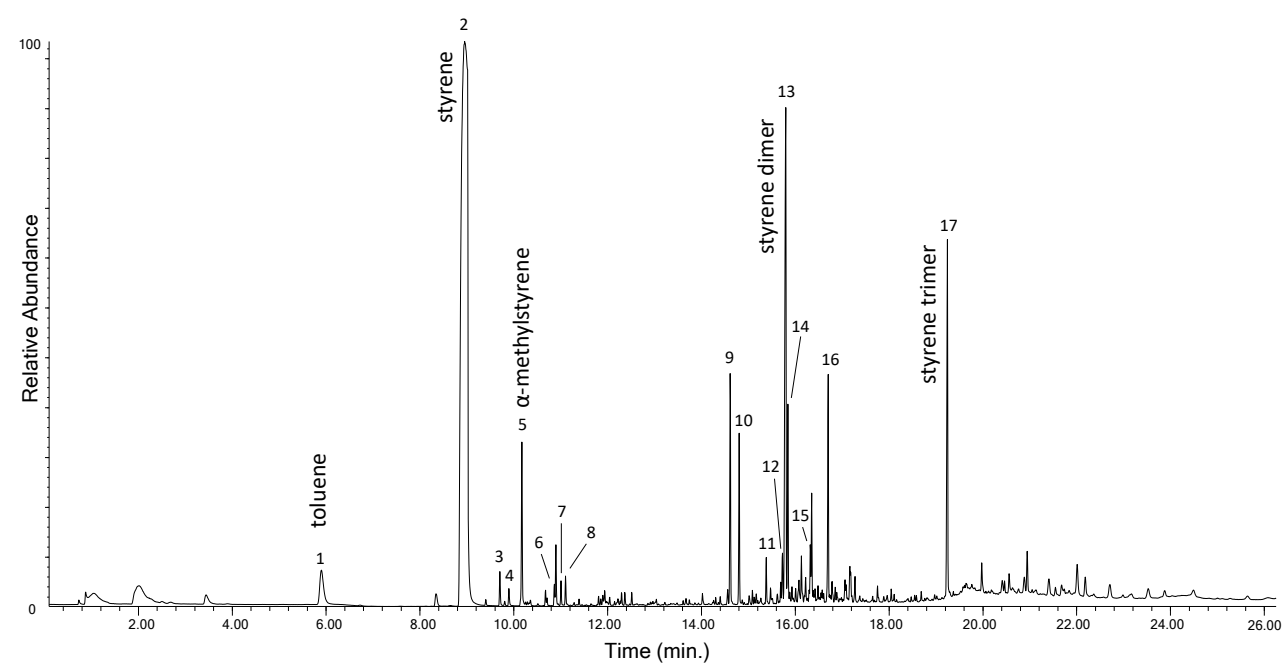

Figure 5 Chromatogram obtained in the Py-GC-MS analysis of the unaged PS (PS-Ow). Peak identification is reported in Table 3.

Table 3 Identification of peaks in the chromatogram obtained in the Py-GC-MS analysis of PS-0w (Figure 5) [20].

\begin{tabular}{|c|c|c|c|}
\hline \# & $\operatorname{tr}(\min )$ & Peak identification & Main ions $(m / z)$ \\
\hline 1 & 6.0 & toluene & $92,91,65$ \\
\hline 2 & 8.9 & styrene & $104,78,63,51$ \\
\hline 3 & 9.7 & allylbenzene & $117,103,91,65$ \\
\hline 4 & 9.9 & benzaldehyde & $106,105,77,51$ \\
\hline 5 & 10.2 & $\alpha$-methylstyrene & $\mathbf{1 1 8}, 103,91,78,63,51$ \\
\hline 6 & 10.8 & 3-butenylbenzene & $132,104,91,65$ \\
\hline 7 & 11.0 & (1-methylenepropyl)-benzene & $132, \mathbf{1 1 7}, 103,91,77,63,51$ \\
\hline 8 & 11.1 & acetophenone & $120,105,91,77,51$ \\
\hline 9 & 14.6 & 1,2-diphenylethane & $182,91,65$ \\
\hline 10 & 14.8 & propane-1,2-diyldibenzene & $196,105,91,77,65$ \\
\hline 11 & 15.4 & 1,1'-(1,3-propanediyl)bis-benzene & $196,105,92,77,65,51$ \\
\hline 12 & 15.7 & stilbene & $180,179,165,152,102,89,76$ \\
\hline 13 & 15.8 & 3-butene-1,3-diyldibenzene (styrene dimer) & $208,193,130,115,104,91,77,65$ \\
\hline 14 & 15.9 & 1-pentene-2,4-diyldibenzen & $222,194,179,115,105,91,77$ \\
\hline 15 & 16.3 & (E)-1-butene-1,4-diyldibenzene & $208,117,115,91,65$ \\
\hline 16 & 16.7 & hexa-1,5-diene-2,5-diyldibenzene & $234,143,130,115,104,91,77,65$ \\
\hline 17 & 19.2 & 5-hexene-1,3,5-triyltribenzene (styrene trimer) & $312,207,194,117,91,77$ \\
\hline
\end{tabular}

\subsubsection{Polyethylene terephthalate (PET)}

The EGA profile of the unaged PET-0w sample (Figure S.4 in Supplementary Materials) shows a peak from $381{ }^{\circ} \mathrm{C}$ to $463^{\circ} \mathrm{C}$ with a maximum (TD) at $410{ }^{\circ} \mathrm{C}$. The EGA profiles of the artificially aged samples do not show any significant variation in the $\mathrm{TD}_{\mathrm{D}}$ or in the relative abundance of the main ions in the average mass spectrum $\left(381-463^{\circ} \mathrm{C}\right.$, Figure $\mathrm{S} .5$ in Supplementary Materials). The latter are fragments with $\mathrm{m} / \mathrm{z}$ 44, 77, 105, 122, 149, 297 
which correspond to the ions in the mass spectra of the thermal degradation of the polymer: vinyl benzoate, benzoic acid, divinyl terephthalate, and 2-(benzoyloxy) ethyl vinyl terephthalate. As in the case of PS, a slight decrease of the onset temperature $\left(\Delta \mathrm{T}=7^{\circ} \mathrm{C}\right)$ is only observed in the EGA profile of the PET- $4 \mathrm{w}$ sample, that can be related to the formation of photo-oxidation products; an extended artificial aging time would be necessary to better investigate the degradation behavior. The chromatogram obtained in the Py-GCMS analysis of the unaged PET-0w is shown in Figure 6, while peak identification is listed in Table 4 . The main pyrolysis products of PET are vinyl benzoate $\left(n^{\circ} 9\right)$, benzoic acid $\left(n^{\circ}\right.$ $10)$, biphenyl $\left(n^{\circ} 11\right)$, divinyl terephthalate $\left(n^{\circ} 12\right)$ and ethan-1,2-divinyldibenzoate $\left(n^{\circ} 18\right)$. The Py-GC-MS profile of the PET- $4 \mathrm{w}$ sample is also in this case very similar to that of the unaged polymer, in agreement with its well-known higher photostability compared to polyolefins [28,32]. In the Py-GC-MS profile of the artificially aged polymer only a slight increase of the relative abundance of acetophenone, benzaldehyde, vinyl benzoate, dibenzofuran, and fluorenone is observed.

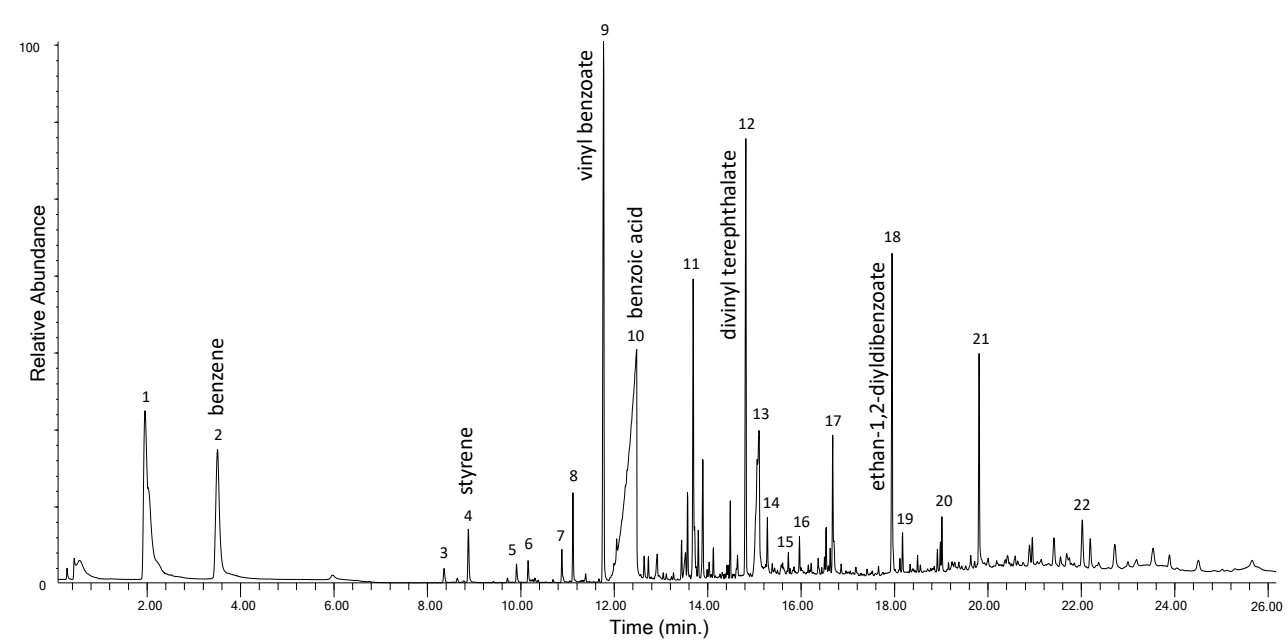

Figure 6 Chromatogram obtained in the Py-GC-MS analysis of the unaged PET (PET-0w). Peak identification is reported in Table 4.

Table 4 Identification of peaks in the chromatogram obtained in the Py-GC-MS analysis of PET- $0 \mathrm{w}$ (Figure 6) [20].

\begin{tabular}{|c|c|c|c|}
\hline \# & $\operatorname{tr}(\min )$ & Peak identification & Main ions $(m / z)$ \\
\hline 1 & 2.0 & carbon dioxide & 44 \\
\hline 2 & 3.5 & benzene & $78,63,51$ \\
\hline 3 & 8.3 & ethylbenzene & $106,91,77,65,51$ \\
\hline 4 & 8.9 & styrene & $104,78,63,51$ \\
\hline 5 & 9.9 & benzaldehyde & $106,105,77,51$ \\
\hline 6 & 10.1 & phenol & $94,79,66,55,39$ \\
\hline 7 & 10.9 & benzeneacetaldehyde & $120,91,65,51$ \\
\hline 8 & 11.1 & acetophenone & $120,105,77,51$ \\
\hline 9 & 11.8 & vinyl benzoate & $148,105,77,51$ \\
\hline 10 & 12.4 & benzoic acid & $122,105,77,51$ \\
\hline 11 & 13.7 & biphenyl & $154,131,115,76$ \\
\hline 12 & 14.8 & divinyl terephthalate & $\mathbf{1 7 5}, 147,132,104,76$ \\
\hline 13 & 15.1 & 4-(vinyloxycarbonyl) benzoic acid & $149,121,76,65$ \\
\hline
\end{tabular}




\begin{tabular}{|c|c|c|c|}
\hline 14 & 15.2 & benzophenone & $182,152,105,77,51$ \\
\hline 15 & 15.7 & stilbene & $180,179,165,152,102,89,76$ \\
\hline 16 & 15.9 & 9H-fluoren-9-one & $180,152,126,76$ \\
\hline 17 & 16.7 & unknown & $198, \mathbf{1 8 1}, 152,76$ \\
\hline 18 & 17.9 & ethan-1,2-divinyldibenzoate & $227,105,77,51$ \\
\hline 19 & 18.2 & unknown & 230, 198, 181, 152, 115 \\
\hline 20 & 19.0 & unknown & $296,149,131,105,77,51$ \\
\hline 21 & 19.8 & 2-(benzoyloxy) ethyl vinyl terephthalate & $297,149,105,77$ \\
\hline 22 & 22.0 & ethan-1,2-diyl divinyl diterephthalate & $367,325,296,175,162,104$ \\
\hline
\end{tabular}

\subsubsection{Polyethylene (PE)}

Both HDPE and LDPE were investigated, both discussed in this section. The EGA profile of the unaged (Figure S.6 in Supplementary Materials) LDPE-0w sample shows a peak with $\mathrm{T}_{\mathrm{D}}$ at $454{ }^{\circ} \mathrm{C}$; artificial aging induces a slight increase of the baseline and a shift $(\Delta \mathrm{T}$ $=7^{\circ} \mathrm{C}$ ) of the onset to lower temperatures, indicative of the formation of oxidation products. No significant changes are observed in the average mass spectra of the artificially aged LDPE samples (Figure S.8 in Supplementary Materials). The main ions are the fragments with $\mathrm{m} / \mathrm{z} 43,57,69,83,97,111,125,139,154$ which correspond to polyethylene oligomers of different chain lengths (Table 5) [20]. The EGA curves of the unaged and aged HDPE samples (Figure S.7 in Supplementary Materials) show a peak with $T_{D}$ at 474 ${ }^{\circ} \mathrm{C}, 20$ degrees higher than that recorder for LDPE samples. Even in this case, artificial aging induces a slight decrease of the onset temperature $\left(\Delta \mathrm{T}=6^{\circ} \mathrm{C}\right)$ probably due to the presence of oxidation products at low concentration as a result of photo-oxidative degradation. The average mass spectra from the EGA profiles of the HDPE samples (Figure S.9 in Supplementary Materials) are equivalent to the LDPE ones. The results obtained in the Py-GC-MS of the LDPE- $0 \mathrm{w}$ are reported in Figure 7 and Table 5. The pyrogram features a series of clusters comprising three main peaks each, assigned to the diene (most likely an $\alpha, \omega$-diene, $\left.\mathrm{C}_{\mathrm{n}: 2}\right)$, the monoalkene (most likely a 1-alkene, $\mathrm{C}_{\mathrm{n}: 1)}$, and the alkane, respectively, for any given $\mathrm{Cn}$ hydrocarbon in the chain lengths range $\mathrm{C}_{6}-\mathrm{C}_{26}$. At the right of each cluster, the peak corresponding to the $\mathrm{C}_{\mathrm{n}-2}$ linear aldehyde is observed, with low relative intensity.

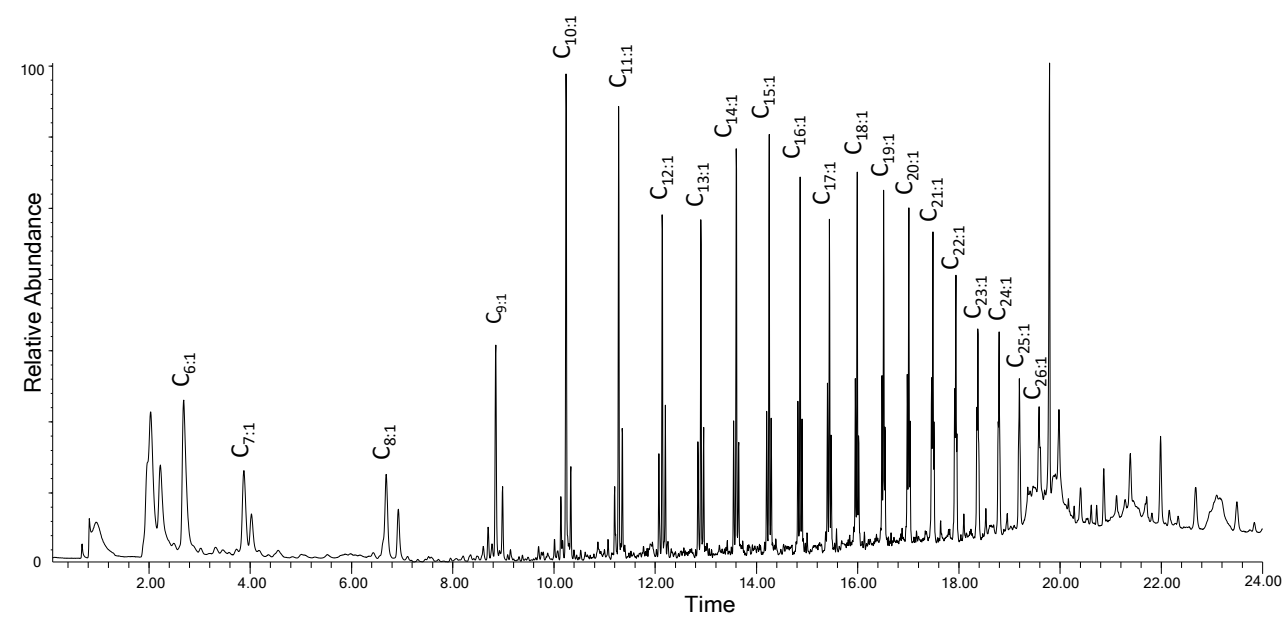

Figure 7 Chromatogram obtained in the Py-GC-MS analysis of the unaged LDPE (LDPE-0w). Cn:1 refers to 1-alkenes of a given $\mathrm{Cn}$ hydrocarbon. Peak identification is reported in Table 5.

Table 5 Identification of peaks in the chromatogram obtained in the Py-GC-MS analysis of LDPE0w (Figure 7) [20]. M+ refers to the molecular ion. 


\begin{tabular}{|c|c|c|c|}
\hline$\#$ & $\operatorname{tr}(\min )$ & Peak identification & Main ions $(m / z)$ \\
\hline 1 & 2.7 & 1-hexene & $84\left(\mathrm{M}^{+}\right), 69,56,41$ \\
\hline 2 & 3.9 & 1-heptene & $98\left(\mathrm{M}^{+}\right), 83,70,56,41$ \\
\hline 3 & 4.0 & heptane & $100\left(\mathrm{M}^{+}\right), 71,57,43$ \\
\hline 4 & 6.7 & 1-octene & $112\left(\mathrm{M}^{+}\right), 97,83,70,55,41$ \\
\hline 5 & 6.9 & octane & $114\left(\mathrm{M}^{+}\right), 85,71,57,43$ \\
\hline 6 & 8.7 & 1,8-nonadiene & $109,96,81,67,55,41$ \\
\hline 7 & 8.8 & 1-nonene & $126\left(\mathrm{M}^{+}\right), 97,83,69,56,41$ \\
\hline 8 & 9.0 & nonane & $128\left(\mathrm{M}^{+}\right), 99,85,71,57,43$ \\
\hline 9 & 10.1 & 1,9-decadiene & $110,95,81,67,55,41$ \\
\hline 10 & 10.2 & 1-decene & $140\left(\mathrm{M}^{+}\right), 111,97,83,70,55,41$ \\
\hline 11 & 10.3 & decane & $142\left(\mathrm{M}^{+}\right), 117,99,85,71,57,43$ \\
\hline 12 & 11.2 & 1,10-undecadiene & $124,109,95,81,67,55,41$ \\
\hline 13 & 11.3 & 1-undecene & $154\left(\mathrm{M}^{+}\right), 126,111,97,83,70,55,43$ \\
\hline 14 & 11.4 & undecane & $156\left(\mathrm{M}^{+}\right), 98,85,71,57,43$ \\
\hline 15 & 12.1 & 1,11-dodecadiene & $138,124,109,95,81,67,55,41$ \\
\hline 16 & 12.13 & 1-dodecene & $168\left(\mathrm{M}^{+}\right), 140,125,111,97,83,69,55,41$ \\
\hline 17 & 12.2 & dodecane & $170\left(\mathrm{M}^{+}\right), 128,85,71,57,43$ \\
\hline 18 & 12.3 & decanal & $138,128,112,95,82,68,55,41$ \\
\hline 19 & 12.8 & 1,12-tridecadiene & $123,109,95,81,67,55,41$ \\
\hline 20 & 12.9 & 1-tridecene & $125,111,97,83,69,55,41$ \\
\hline 21 & 13.0 & tridecane & $184\left(\mathrm{M}^{+}\right), 99,85,71, \mathbf{5 7}, 43$ \\
\hline 22 & 13.05 & undecanal & $152,126,109,96,82,68,55,41$ \\
\hline 23 & 13.5 & 1,13-tetradecadiene & $123,109,96,81,67,55,41$ \\
\hline 24 & 13.6 & 1-tetradecene & $125,111,97,83,69,55,41$ \\
\hline 25 & 13.64 & tetradecane & $198\left(\mathrm{M}^{+}\right), 99,85,71, \mathbf{5 7}, 43$ \\
\hline 26 & 13.72 & dodecanal & $166,140,123,110,96,82,68,57,41$ \\
\hline 27 & 14.2 & 1,14-pentadecadiene & $123,109,96,81,67,55,41$ \\
\hline 28 & 14.25 & 1-pentadecene & $210\left(\mathrm{M}^{+}\right), 125,111,97,83,69,55,41$ \\
\hline 29 & 14.3 & pentadecane & $212\left(\mathrm{M}^{+}\right), 113,99,85,71,57,43$ \\
\hline 30 & 14.4 & tridecanal & $180,154,124,110,96,82,68,57,43$ \\
\hline 31 & 14.8 & 1,15-hexadecadiene & $123,109,96,82,67,55,41$ \\
\hline 32 & 14.86 & 1-hexadecene & $224\left(\mathrm{M}^{+}\right), 125,111,97,83,69,55,41$ \\
\hline 33 & 14.9 & hexadecane & $226\left(\mathrm{M}^{+}\right), 99,85,71,57,43$ \\
\hline 34 & 15.0 & tetradecanal & $194,168,138,110,96,82,69,57,41$ \\
\hline 35 & 15.4 & 1,16-heptadecadiene & $137,123,109,96,82,69,55,41$ \\
\hline 36 & 15.44 & 1-heptadecene & $238\left(\mathrm{M}^{+}\right), 139,125,111,97,83,69,55,41$ \\
\hline 37 & 15.5 & heptadecane & $240\left(\mathrm{M}^{+}\right), 99,85,71,57,43$ \\
\hline 38 & 15.6 & pentadecanal & $208,180,111,96,82,69,57,41$ \\
\hline 39 & 15.9 & 1,17-octadecadiene & $123,109,96,82,69,55,41$ \\
\hline 40 & 16.0 & 1-octadecene & $252\left(\mathrm{M}^{+}\right), 125,111,97,83,69,55,41$ \\
\hline 41 & 16.02 & octadecane & $254\left(\mathrm{M}^{+}\right), 99,85,71,57,43$ \\
\hline
\end{tabular}




\begin{tabular}{|c|c|c|c|}
\hline 42 & 16.1 & hexadecanal & $222,124,111,96,82,69,57,43$ \\
\hline 43 & 16.5 & 1,18-nonadecadiene & $137,123,109,96,82,69,55,41$ \\
\hline 44 & 16.51 & 1-nonadecene & $139,125,111,97,83,69,55,43$ \\
\hline 45 & 16.54 & nonadecane & $268\left(\mathrm{M}^{+}\right), 127,113,99,85,71,57,43$ \\
\hline 46 & 16.7 & heptadecanal & $236,208,137,124,109,96,82,68,57,41$ \\
\hline 47 & 16.97 & 1,19-eicosadiene & $137,123,109,96,82,69,55,41$ \\
\hline 48 & 17.01 & 1-eicosene & $139,125,111,97,83,69,55,43$ \\
\hline 49 & 17.04 & eicosane & $127,113,99,85,71,57,43$ \\
\hline 50 & 17.1 & octadecanal & $250,137,124,109,96,82,68,57,43$ \\
\hline 51 & 17.4 & 1,20-heneicosadiene & $137,123,109,96,82,69,55,41$ \\
\hline 52 & 17.48 & 1-heneicosene & $139,125,111,97,83,69,55,43$ \\
\hline 53 & 17.50 & heneicosane & $113,97,85,71,57,43$ \\
\hline 54 & 17.6 & nonadecanal & $264,202,137,124,110,97,82,69,57,43$ \\
\hline 55 & 17.91 & 1,21-docosadiene & $151,137,123,109,96,82,67,55,41$ \\
\hline 56 & 17.94 & 1-docosene & $139,125,111,97,83,69,55,43$ \\
\hline 57 & 17.96 & docosane & $310\left(\mathrm{M}^{+}\right), 99,85,71,57,43$ \\
\hline 58 & 18.1 & eicosanal & $278,250,123,111,96,82,69,57,43$ \\
\hline 59 & 18.3 & 1,22-tricosadiene & $137,123,109,96,82,69,55,41$ \\
\hline 60 & 18.37 & 1-tricosene & $322\left(\mathrm{M}^{+}\right), 125,111,97,83,69,55,43$ \\
\hline 61 & 18.39 & tricosane & $324\left(\mathrm{M}^{+}\right), 113,97,85,71,57,43$ \\
\hline 62 & 18.5 & heneicosanal & $292,138,123,111,96,82,68,57,43$ \\
\hline 63 & 18.77 & 1,23-tetracosadiene & $334\left(\mathrm{M}^{+}\right), 137,123,109,96,82,69,55,41$ \\
\hline 64 & 18.8 & 1-tetracosene & $336\left(\mathrm{M}^{+}\right), 139,125,111,97,83,69,57,43$ \\
\hline 65 & 19.0 & docosanal & $306,251,138,124,111,96,82,71,57,43$ \\
\hline 66 & 19.2 & 1-pentacosene & $350\left(\mathrm{M}^{+}\right), 139,125,111,97,83,69,57,43$ \\
\hline 67 & 19.35 & tricosanal & $320,139,125,111,97,83,71,57,43$ \\
\hline 68 & 19.6 & 1-hexacosene & $364\left(\mathrm{M}^{+}\right), 139,125,111,97,83,69,57,43$ \\
\hline 69 & 19.8 & unknown & $297,149,105,77$ \\
\hline
\end{tabular}

After artificial aging, new peaks next to the triplets are observed in the pyrolytic profiles of both HDPE and LDPE, that can be associated to oxidation products and in particular to linear ketones, linear saturated alcohols, and monocarboxylic acids. Peaks corresponding to saturated aldehydes, with lengths up to $\mathrm{C} 24$, increase in their relative intensity with aging (Figure 8) [33]. The complete list of all the pyrolysis products detected in the chromatogram obtained in the Py-GC-MS analysis of LDPE- $4 \mathrm{w}$ is reported in Table S.1 in the Supplementary Materials. The oxidation products detected in the chromatogram can either be the products of the thermolytic cleavage of oxidized high molecular weight polymer chains, or smaller oxidized fragments produced by photolytic oxidation and chain scission as a result of photo-oxidative artificial aging, or both. Even though the general features of the pyrolysis profiles of the two aged polymers are very similar, in the case of LDPE a slightly higher number of oxidized pyrolysis products were detected compared to HDPE. Tables S.2 and S.3 report the complete list of the pyrolysis products identified in the chromatogram obtained in the Py-GC-MS analysis of the HDPE- $0 w$ and HDPE- $4 w$ samples, respectively. 


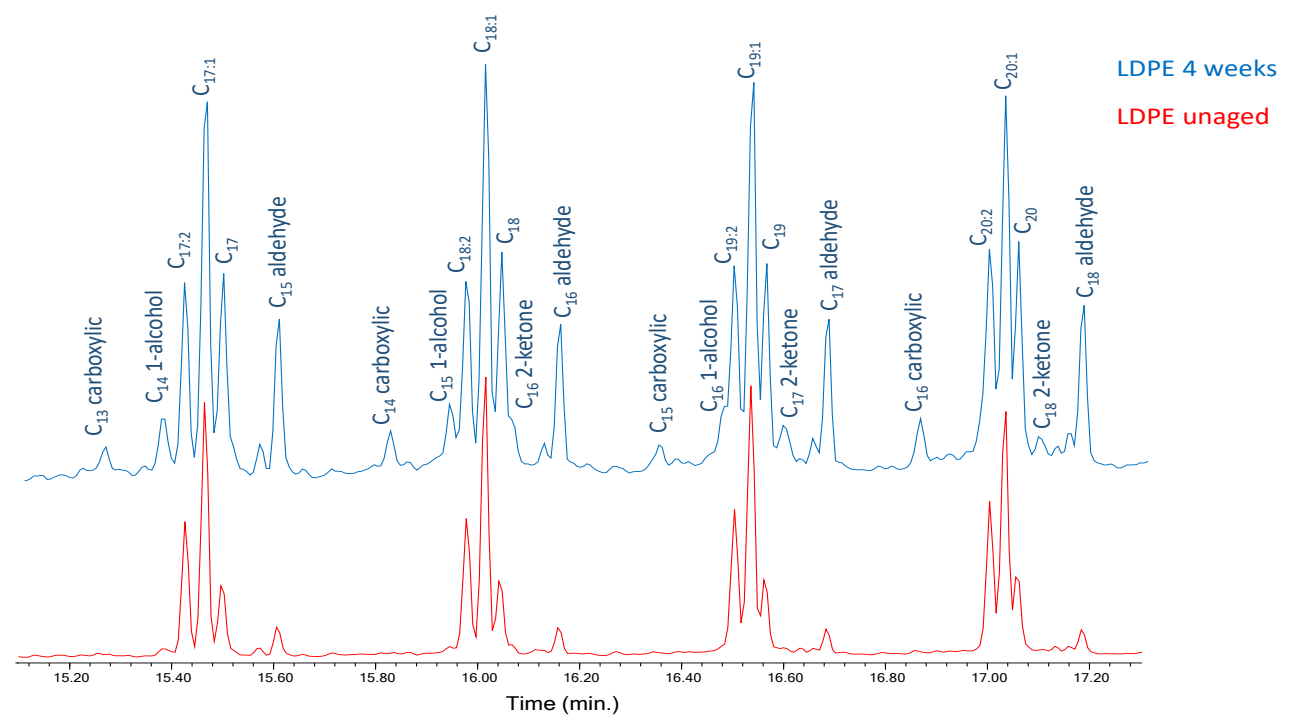

Figure 8 Chromatograms (15.20 - $17.20 \mathrm{~min}$ ) obtained in the Py-GC-MS analysis of LDPE-0w (red) and LDPE-4w (blue). $\mathrm{C}_{\mathrm{n}: 2}$ refers to $\alpha, \omega$-dienes, $\mathrm{Cn}: 1$ to 1 -alkenes, and $\mathrm{Cn}$ to alkanes of a hydrocarbon with $\mathrm{n}$ carbon atoms.

\subsection{Analysis of extractable fraction of reference polymers before and after artificial aging}

The presence of low amounts of low molecular weight degradation and oxidation products may not be detectable by Py-GC-MS analysis of the aged polymer, because the peaks deriving from the unaltered fraction of the polymer could hinder the detection of lowintensity peaks associated to the altered portion of the polymer. For this reason, the alteration induced on the five reference plastics by the photoaging was investigated also by a complementary approach: the aged samples were extracted with polar organic solvent and the composition of the extracts was investigated by size-exclusion chromatography (SEC) and Py-GC-MS, and compared with the extracts obtained from the unaged corresponding polymer. PP, PET, HDPE, and LDPE were subjected to DCM extraction, while $\mathrm{MeOH}$ was used for PS. Procedural blanks were also prepared for comparison. Py-GCMS analysis of the extractable fractions allowed us to achieve an enhanced sensitivity towards the degradation products, focusing on the extractable and leachable components to gain additional information on the degradation processes occurring during the aging of MPs. Py-GC-MS was carried out with the addition of HMDS in order to detect and characterize the low-volatile and polar compounds such as aldehydes, alcohols and carboxylic acids strictly related to photo-oxidative degradation; HMDS also achieves the derivatization of PET pyrolysis products.

\subsubsection{Polypropylene}

The chromatogram obtained in the Py(HMDS)-GC-MS analysis of the DCM extract of the PP-4w sample is reported in Figure 9, with peak identification in Table 6. The pyrolytic profile shows oxidized products such as different chain length mono- and dicarboxylic acid in the first part of the chromatogram (14-24 min). In particular, low-molecular weight differently branched monocarboxylic acids are detected in the $\mathrm{C}_{2}-\mathrm{C}_{6}$ range, such as butanoic acid $\left(\mathrm{n}^{\circ} 5\right), 2$-butenoic acid $\left(\mathrm{n}^{\circ} 6\right)$, 2-methyl-4-pentenoic acid $\left(\mathrm{n}^{\circ} 8\right), 3$-methyl-3-butenoic acid $\left(n^{\circ} 9\right)$, 2-hydroxypropanoic acid $\left(n^{\circ} 12\right)$, hydroxyacetic acid $\left(n^{\circ} 13\right)$ 2-hydroxy2-propenoic acid ( $\left.{ }^{\circ} 15\right), 2$-hydroxybutanoic acid ( $\left.{ }^{\circ} 16\right)$, 4-oxopentanoic acid ( $\left.\mathrm{n}^{\circ} 17\right), 3$ hydroxypropanoic acid ( $\left.{ }^{\circ} 18\right)$, 3-hydroxybutanoic acid ( $\left.{ }^{\circ} 19\right)$, and 3-hydroxy-3-butenoic acid $\left(n^{\circ} 20\right)$. Low molecular weight dicarboxylic acids such as butanedioic acid $\left(n^{\circ} 22\right)$ and methylbutanedioic acid $\left(n^{\circ} 23\right)$ are also observed in the first part of the profile. The second 
part of the chromatogram (24-35 $\mathrm{min})$ is mainly characterized by different chain-length PP oligomers that are soluble in DCM.

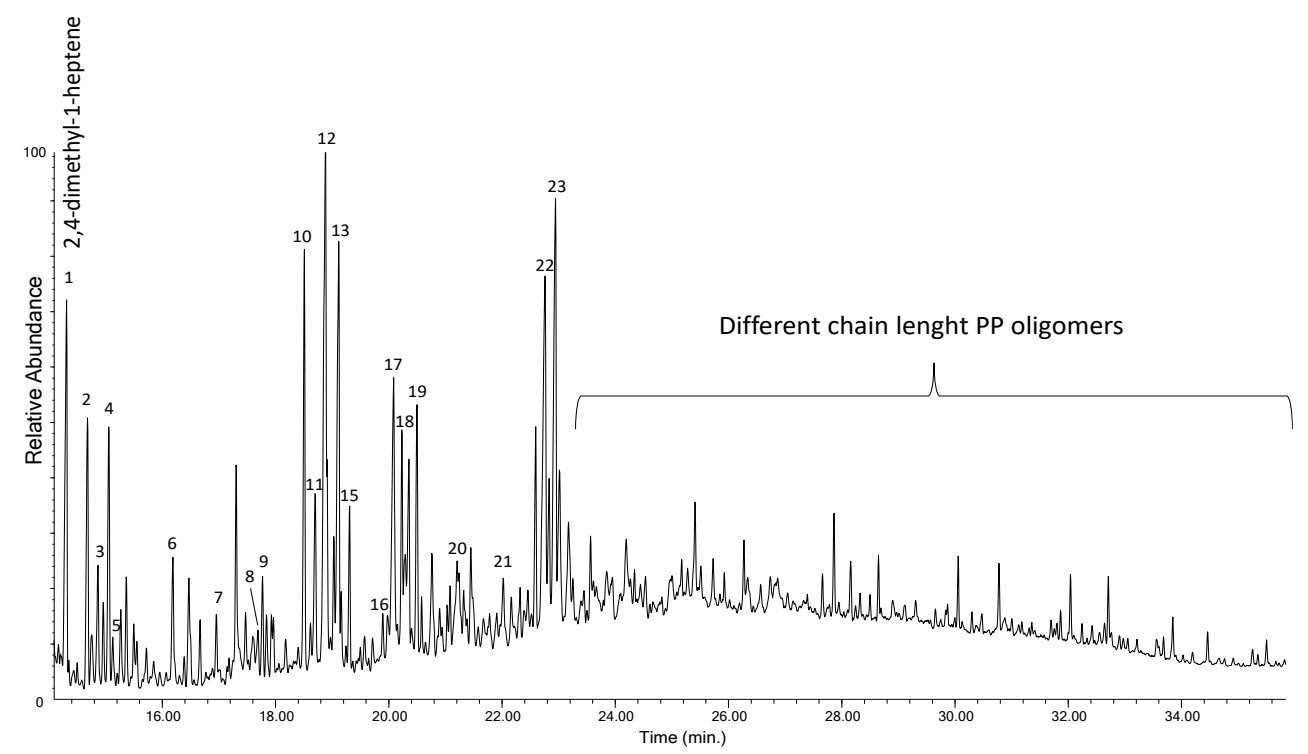

Figure 9 Chromatogram obtained in the Py(HMDS)-GC-MS analysis of the DCM extract of PP-4w. Peak identification is reported in Table 6.

Table 6 Identification of peaks in the chromatogram obtained in the Py(HMDS)-GC-MS analysis of the DCM extract of PP-4w (Figure 9). Bold: most abundant species in the chromatogram.

\begin{tabular}{|c|c|c|c|}
\hline \# & $\operatorname{tr}(\min )$ & Peak identification & Main ions $(m / z)$ \\
\hline 1 & 14.3 & 2,4-dimethyl-1-heptene & $126,83,70,55$ \\
\hline 2 & 14.7 & xylene & 106,91 \\
\hline 3 & 14.9 & ethoxytriethylsilane & $131,103,73$ \\
\hline 4 & 15.05 & octamethyltrisiloxane & 221,73 \\
\hline 5 & 15.1 & butanoic acid, trimethylsilyl ester & $145,117,75$ \\
\hline 6 & 16.2 & 2-butenoic acid, tert-butyldimethylsilyl ester & $143,99,75,59$ \\
\hline 7 & 16.9 & 1,2,3-trimethylbenzene & 120,105 \\
\hline 8 & 17.6 & 4-pentenoic acid, 2-methyl, trimethylsilyl ester & $186,171,157,117,73$ \\
\hline 9 & 17.8 & 3-butenoic acid,3-methyl, trimethylsilyl ester & $172,157,127,113,73,54$ \\
\hline 10 & 18.5 & methyltris(trimethylsiloxy)silane & $295,207,191,73$ \\
\hline 11 & 18.7 & unknown & $171,146,133,117,73$ \\
\hline 12 & 18.9 & propanoic acid, 2-[(trimethylsilyl)oxy]-, trimethylsilyl ester & $233,129,191,147,133,117,73$ \\
\hline 13 & 19.1 & acetic acid, [(trimethylsilyl)oxy]-, trimethylsilyl ester & $205,190,161,147,133,117,103$ \\
\hline 14 & 19.2 & unknown & $171,157,145,129,117,103,75$ \\
\hline 15 & 19.3 & 2-propenoic acid, 2-[(trimethylsilyl)oxy]-, trimetylsilyl ester & $217,147,131,73$ \\
\hline 16 & 19.9 & butanoic acid, 2-[(trimethylsilyl)oxy]-, trimethylsilyl ester & $233,205,190,147,131,73$ \\
\hline 17 & 20.1 & pentanoic acid, 4-oxo-, trimethylsilyl ester & $173,155,145,131,75$ \\
\hline 18 & 20.2 & propanoic acid, 3-[(trimethylsilyl)oxy]-, trimethylsilyl ester & $219,177,147,133,116,73$ \\
\hline 19 & 20.5 & butanoic acid, 3-[(trimethylsilyl)oxy]-, trimethylsilyl ester & $223,191,147,130,117,73$ \\
\hline 20 & 21.2 & 3-butenoic acid,3-(trimethylsilyloxy)-,trimethylsilyl ester & $231,157,147,73$ \\
\hline 21 & 22.1 & malic acid, O-(trimethylsilyl)-, bis(trimethylsilyl) ester & $245,233,147,73$ \\
\hline 22 & 22.7 & butanedioic acid, bis(trimethylsilyl) ester & $247,147,129,73$ \\
\hline
\end{tabular}


These oxidized products could not be detected in the pyrogram of the aged bulk sample analyzed without in situ thermally assisted derivatization with HMDS of the carboxylic/hydroxyl functions, due both to their low concentration in the bulk polymer, and to their polarity - low volatility - that made them unsuitable as such for GC separation. The carboxylic and dicarboxylic acids observed in the Py-GC-MS analysis of the extract of artificially aged PP- $4 \mathrm{w}$ are not detected in the extract of unaged PP-0w (Figure S.10 in Supplementary Materials), clearly indicating that they are the result of photo-oxidative degradation rather than of pyrolytic fragmentation. Figure 10 reports the SEC chromatograms (10-25 min) obtained for the DCM extracts of PP-0w (red), PP-1w (green), PP-3w (yellow), and PP-4w (blue). The profiles show two peaks at high retention times (about 20.4 minutes and 22.5 minutes) corresponding to low molecular weight fractions. This is expected since high molecular weight polyolefins are insoluble in DCM. No significant differences are highlighted when comparing the SEC profiles of the unaged and aged PP extracts.

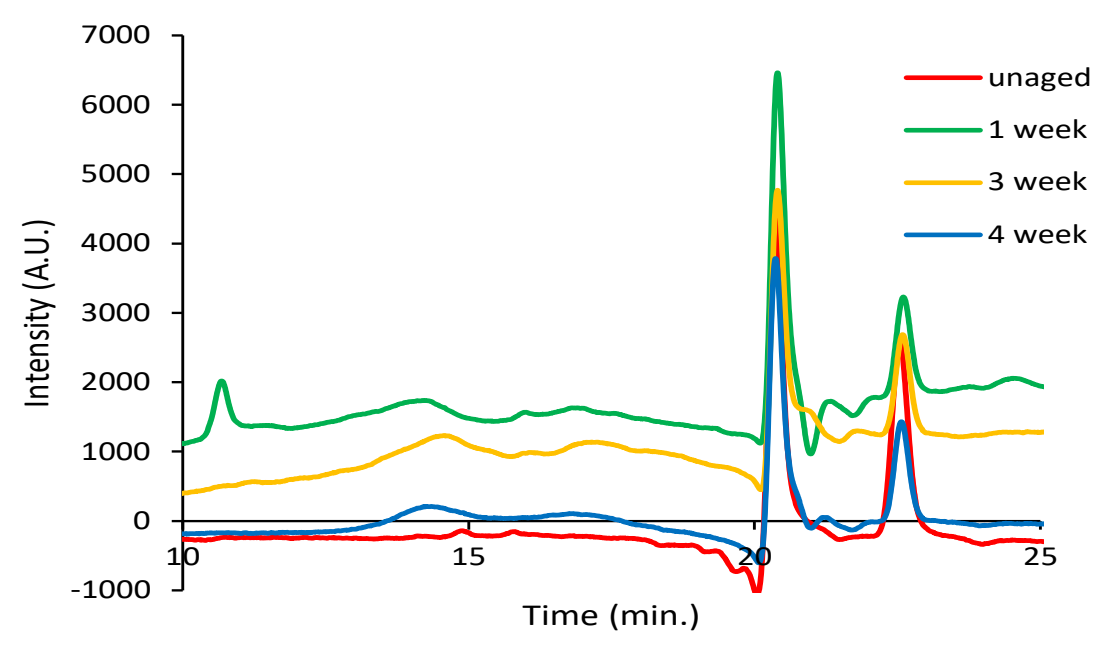

Figure 10 SEC chromatograms (10-25 min) of the DCM extracts of PP-0w (red), PP-1w (green), PP$3 \mathrm{w}$ (yellow), and PP-4w (blue); refractive index detector was used.

\subsubsection{Polystyrene}

The chromatogram obtained in the Py(HMDS)-GC-MS analysis of the $\mathrm{MeOH}$ extract of PS-4 $w$ is reported in Figure 11. Peak identification is in Table 7. The main pyrolysis products are the same as those observed in the Py-GC-MS chromatogram of PS- $4 \mathrm{w}$ analyzed in "bulk" (non-subjected to extraction, Figure 5): styrene $\left(n^{\circ} 2\right)$, benzoic acid $\left(n^{\circ} 26\right)$, its dimer $\left(n^{\circ} 39\right)$, and its trimer $\left(n^{\circ} 53\right)$. Different acids and alcohols deriving from benzoic acid are detected, like 4-methylphenol $\left(\mathrm{n}^{\circ} 20\right)$, 1-phenylethenol $\left(\mathrm{n}^{\circ} 25\right), 3$-methylphenol $\left(n^{\circ} 27\right)$, phenylacetic acid ( $\left.n^{\circ} 28\right)$, phenylpropanoic acid $\left(n^{\circ} 32\right)$, and 4-hydroxybenzoic acid ( $\left.{ }^{\circ} 36\right)$; dicarboxylic acids and other carboxylic acids are also found: 2-hydroxy-propanoic acid $\left(\mathrm{n}^{\circ} 14\right)$, hydroxyacetic acid $\left(\mathrm{n}^{\circ} 16\right)$, 4-hydroxy pentanoic acid $\left(\mathrm{n}^{\circ} 17\right)$, 3-hydroxypropanoic acid $\left(n^{\circ} 19\right)$, butanedioic acid $\left(n^{\circ} 29\right)$, methylbutanedioic acid $\left(n^{\circ} 30\right), 1,4-$ benzenedicarboxylic acid $\left(n^{\circ} 42\right)$, pentadecanoic acid $\left(n^{\circ} 48\right)$, hexadecenoic acid $\left(n^{\circ} 51\right)$, and octadecanoic acid ( $\left.{ }^{\circ} 52\right)$. 


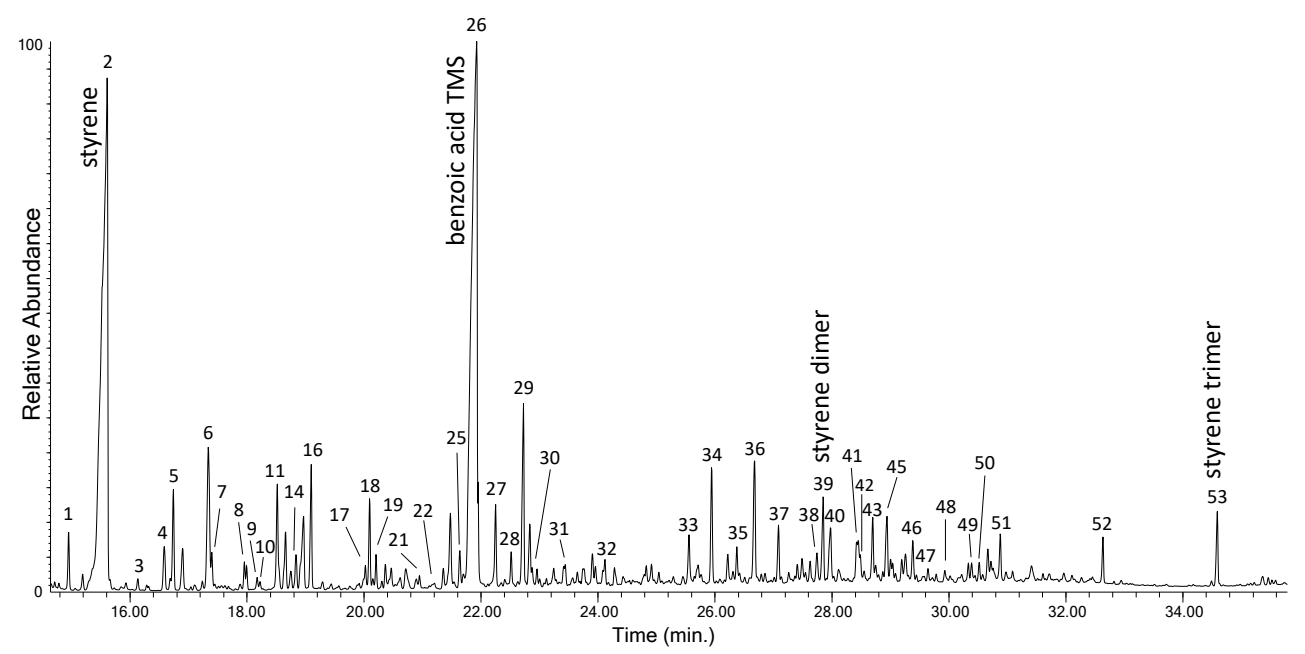

Figure 11 Chromatogram obtained in the Py(HMDS)-GC-MS analysis of the MeOH extract of PS$4 \mathrm{w}$. Peak identification is reported in Table 7.

Table 7 Identification of peaks in the chromatogram obtained in the Py(HMDS)-GC-MS analysis of the MeOH extract of PS-4w (Figure 11). Bold: most abundant species in the chromatogram.

\begin{tabular}{|c|c|c|c|}
\hline$\#$ & $\operatorname{tr}(\min )$ & Peak identification & Main ions $(m / z)$ \\
\hline 1 & 14.9 & ethylbenzene & $106,91,77,65,51$ \\
\hline 2 & 15.5 & styrene & $104,89,78,63,51$ \\
\hline 3 & 16.1 & benzene, (1-methylethyl)- & $120,105,91,77,51$ \\
\hline 4 & 16.6 & unknown & $175,146,132,115,102$ \\
\hline 5 & 16.7 & HMDS unknown & $222,206,190,132,74$ \\
\hline 6 & 17.3 & HMDS unknown & $220,207,188,132,73$ \\
\hline 7 & 17.4 & cyclotrisiloxane, hexamethyl- & 207, 191, 133, 96 \\
\hline 8 & 17.9 & cyclotetrasiloxane, octamethyl- & $281,265,207,191,133,73$ \\
\hline 9 & 18.1 & benzene, 1-propenyl- & $117,103,91,77,63,51$ \\
\hline 10 & 18.2 & benzene, (1-methylene-2-propenyl)- & $130,115,102,91,77,63,51$ \\
\hline 11 & 18.5 & tetrasiloxane, decamethyl- & $295, \mathbf{2 0 7}, 191,73$ \\
\hline 12 & 18.6 & silane, trimethylphenoxy- & $166, \mathbf{1 5 1}, 135,91,77$ \\
\hline 13 & 18.7 & benzene, (1-methylenepropyl)- & $132,117,103,91,77,63,51$ \\
\hline 14 & 18.8 & propanoic acid, 2-[(trimethylsilyl)oxy]-, trimethylsilyl ester & $191,147,133,117,73$ \\
\hline 15 & 18.9 & acetophenone & $120,105,77,51$ \\
\hline 16 & 19.1 & acetic acid, [trimethylsilyl)oxy]-, trimethylsilyl ester & $205,177,147,133,73$ \\
\hline 17 & 20.0 & pentanoic acid, 4-oxo, trimethylsilyl ester & $173,145,131,75$ \\
\hline 18 & 20.1 & 4,6-dioxa-5-aza-2,3,7,8-tetrasilanonane-2,2,3,3,7,7,8,8-octamethyl- & $294,206,190,130,73$ \\
\hline 19 & 20.2 & propanoic acid, 3-[(trimethylsilyl)oxy]-, trimethylsilyl ester & $219,177,147,133,116,73$ \\
\hline 20 & 20.3 & silane, trimethyl(4-methylphenoxy)- & $180,165,149,135,91$ \\
\hline 21 & 20.9 & cyclopentasiloxane, decamethyl & $355,267,251,187,73$ \\
\hline 22 & 21.2 & propanedioic acid, bis(trimethylsilyl) ester & $233,179,147,73$ \\
\hline 23 & 21.3 & pentasiloxane, dodecamethyl- & $369,353,281,265,207,147,43$ \\
\hline 24 & 21.6 & unknown & $281,192,117,151,135,115,73$ \\
\hline 25 & 21.7 & 1-phenyl-1-(trimethylsilyloxy)ethylene & $191,177,135,103,91,75$ \\
\hline
\end{tabular}




\begin{tabular}{|c|c|c|c|}
\hline 26 & 21.9 & benzoic acid trimethylsilyl ester & $194,179,135,105,77,51$ \\
\hline 27 & 22.2 & 1-dimethylvinylsilyloxy-3-methylbenzene & $192,117,165,151,135,91$ \\
\hline 28 & 22.5 & phenylacetic acid, trimethylsilyl ester & $193,164,91,73$ \\
\hline 29 & 22.7 & butanedioic acid, bis(trimethylsilyl) ester & $147,172,147,73$ \\
\hline 30 & 22.9 & butanedioic acid, methyl-, bis(trimethylsilyl) ester & $261,217,147,73$ \\
\hline 31 & 23.4 & hexasiloxane, tetradecamethyl- & $443,355,281,267,221,147,73$ \\
\hline 32 & 24.1 & phenylpropanoic acid, trimethylsilyl ester & $222,207,104,91,75$ \\
\hline 33 & 25.5 & bibenzyl & $182,91,65$ \\
\hline 34 & 25.9 & 1-pentene-2,4-diyldibenzen & $194,115,105,91$ \\
\hline 35 & 26.4 & benzene, 1,1'-(1,2-dimethyl-1,2-ethanediyl)bis- & $210,105,91,77$ \\
\hline 36 & 26.7 & benzoic acid, 4-[(trimethylsilyl)oxy]-, trimethylsilyl ester & $282,267,223,193,73$ \\
\hline 37 & 27.1 & benzene, 1,1'-(1,3-propanediy)bis- & $196,117,105,92,77,65,51$ \\
\hline 38 & 27.7 & stilbene & $179,165,152,102,89,76,51$ \\
\hline 39 & 27.8 & 3-butene-1,3-diyldibenzene (styrene dimer) & $208,130,115,104,91,77,65$ \\
\hline 40 & 28.0 & unknown & $194,165,152,115,91,77,51$ \\
\hline 41 & 28.4 & 1H-indene, 2-phenyl- & $192,165,115,91$ \\
\hline 42 & 28.5 & 1,4-benzenedicarboxylic acid, bis(trimethylsilyl) ester & $310,295,251,221,140,103,73$ \\
\hline 43 & 28.7 & naphthalene, 1,2-dihydro-4-phenyl- & $206,191,128,115,91$ \\
\hline 44 & 28.8 & anthracene & $\mathbf{1 7 8}, 152,89,76$ \\
\hline 45 & 28.9 & 1,3-butadiene, 1,4-diphenyl- & $206,191,178,165,128,115,91$ \\
\hline 46 & 29.4 & naphthalene, 1-phenyl- & $204,101,89$ \\
\hline 47 & 29.6 & 2,5-diphenyl-1,5-hexadiene & $234,143,130,115,104,91,77$ \\
\hline 48 & 29.9 & pentadecanoic acid, trimethylsilyl ester & $297,145,129,117,73$ \\
\hline 49 & 30.4 & fluoranthene, 1,2,3,10b-tetrahydro- & $206,190,178,165,152,89,76$ \\
\hline 50 & 30.5 & naphthalene, 2-phenyl & $204,101,89$ \\
\hline 51 & 30.9 & hexadecanoic acid, trimethylsilyl ester & $328,313,145,129,117,73$ \\
\hline 52 & 32.6 & octadecanoic acid, trimethylsilyl ester & $341,145,129,117,73$ \\
\hline 53 & 34.6 & 5-hexene-1,3,5-triyltribenzene (styrene trimer) & $312,207,194,117,91,77$ \\
\hline
\end{tabular}

By comparing the pyrolysis profiles of the MeOH extracts of PS- $4 \mathrm{w}$ and PS- $0 \mathrm{w}$ samples, none of the oxidized compounds identified by analyzing the extract of PS-4w are detected in the extract of the PS-0w (Figure S.11 in Supplementary Materials), indicating that these compounds are the result of extensive photo-oxidative degradation occurred during artificial aging. Figures 12.a and 12.b report the SEC chromatograms $(10-27 \mathrm{~min}$.) of the $\mathrm{MeOH}$ extracts of PS-0w (red), PS-1w (green), PS- $2 \mathrm{w}$ (purple), PS-3w (yellow), PS- $4 \mathrm{w}$ (blue), acquired at $260 \mathrm{~nm}$ and $340 \mathrm{~nm}$, respectively. 
a)

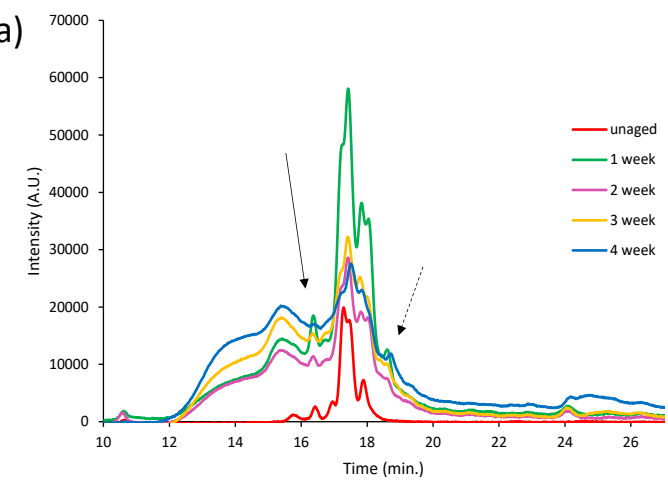

b)

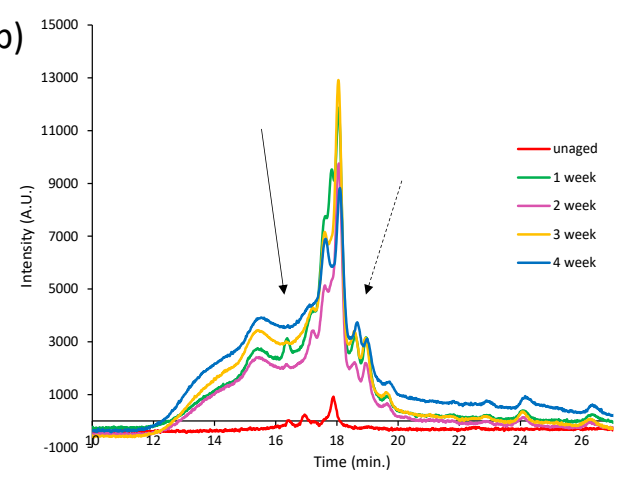

Figure 12 SEC chromatograms (10-27 min) of the MeOH extracts of PS-0w (red), PS-1w (green), PS2w, PS-3w (yellow), and PS-4w (blue) acquired at $260 \mathrm{~nm}$ (a) and $340 \mathrm{~nm}$ (b).

The extracts of the aged PS samples show a broad structured band in the 12-20 minutes time range, which corresponds to fractions with molecular weight ranging from $10200 \mathrm{Da}$ to values below $500 \mathrm{Da}$; whereas the profile of the extract of the PS-0w (red) appears lessintense in the $260 \mathrm{~nm}$ chromatogram, and it is almost non-detectable in the $340 \mathrm{~nm}$ chromatogram, showing a band in the 16-19 minutes time range. Aging induces the disappearance of the peak at 16 minutes (black arrow) and the appearance of a new one at about 19 minutes (dotted black arrow) which corresponds to low-molecular weight fraction (below $500 \mathrm{Da}$ ). This suggests that with aging, cross-linking reactions occurs, along with chain scission reactions that lead to the formation of low-molecular weight products (i.e. styrene dimers and trimers).

\subsubsection{Polyethylene terephthalate}

The chromatogram obtained in the Py(HMDS)-GC-MS analysis of the DCM extract of the PET-4w sample is reported in Figure 13, with peak identification in Table 8. The pyrograms of the DCM extract of PET-0w and PET- $4 w$ samples are very similar, in agreement with the results obtained by EGA-MS and Py-GC-MS for the bulk (non-extracted) polymer, highlighting PET photo-oxidative stability. In particular, the typical pyrolysis products of the polymer are observed: benzoic acid $\left(\mathrm{n}^{\circ} 14\right)$, vinyl benzoate $\left(\mathrm{n}^{\circ} 22\right)$, and divinyl terephthalate $\left(n^{\circ} 24\right)$. The identified carboxylic acids and benzenedicarboxylic acids - hydroxybenzoic acid ( $\left.n^{\circ} 11\right), 3$-phenyl-2-propenoic acid $\left(\mathrm{n}^{\circ} 20\right)$ and 1,4-benezenedicarboxylic acid $\left(n^{\circ} 26\right)$ - were also present in the pyrogram of the DCM extract of the unaged sample, suggesting that they are not the result of photo-oxidative degradation but more likely they are the result of thermolytic cleavage and rearrangements occurring during pyrolysis.

PET extracts were not analyzed by means of SEC since the amount of the extractable fraction and the pyrolysis profiles of the extracts of PET- $0 \mathrm{w}$ and PET- $4 \mathrm{w}$ samples were nearly identical. The content of the extract is thus the intrinsically DCM-soluble fraction of the polymer, and it can be assumed that it does not derive from degradation phenomena of the polymer. 


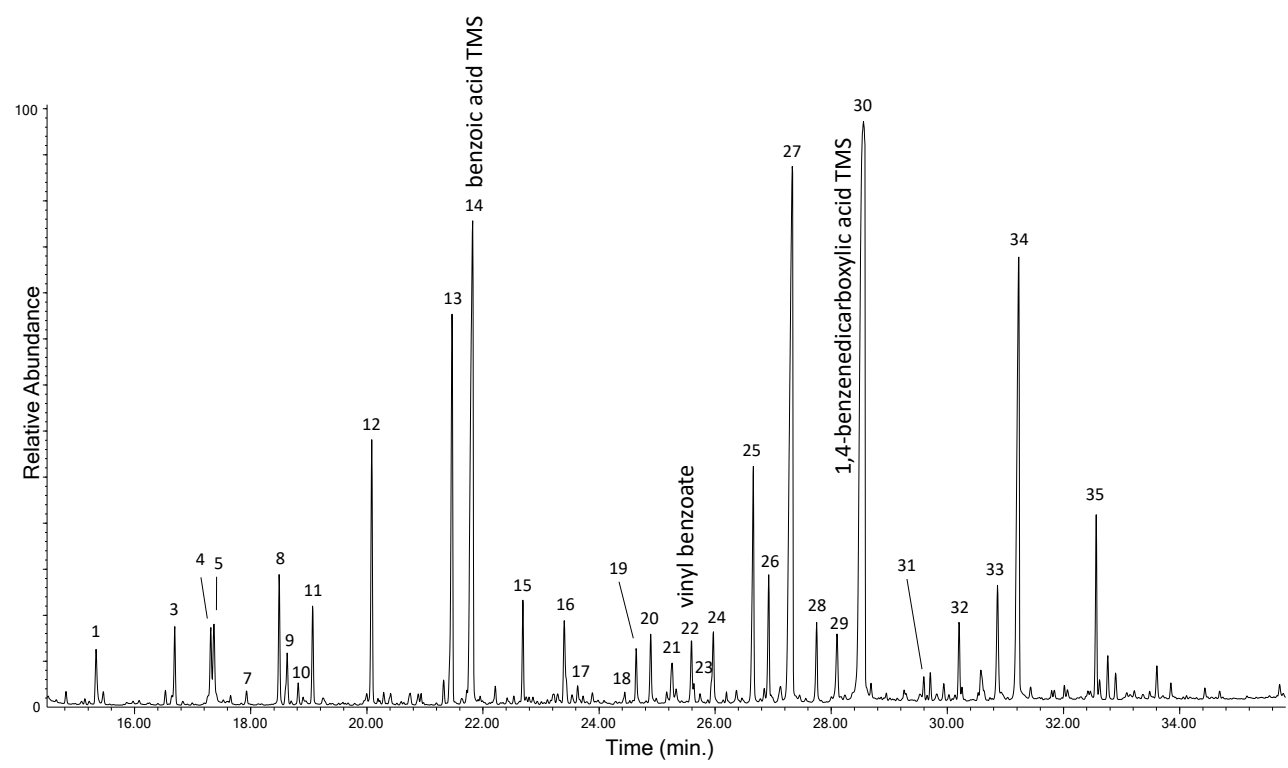

Figure 13 Chromatogram obtained in the Py(HMDS)-GC-MS analysis of the DCM extract of PET$4 \mathrm{w}$. Peak identification is reported in Table 8.

Table 8 Identification of peaks in the chromatogram obtained in the Py(HMDS)-GC-MS analysis of the DCM extract of PET-4w (Figure 13). Bold: most abundant species in the chromatogram.

\begin{tabular}{|c|c|c|c|}
\hline$\#$ & $\operatorname{tr}(\min )$ & Peak identification & Main ions $(m / z)$ \\
\hline 1 & 15.3 & styrene & $104,89,78,63,51$ \\
\hline 2 & 16.4 & unknown & $175,146,132,115,73$ \\
\hline 3 & 16.7 & HMDS unknown & $222,206,190,132,74$ \\
\hline 4 & 17.2 & HMDS unknown & $220,204,132,73$ \\
\hline 5 & 17.3 & HMDS unknown & $220,207,188,132,73$ \\
\hline 6 & 17.4 & unknown & $223,207,191,147,73$ \\
\hline 7 & 17.9 & cyclotetrasiloxane, octamethyl & $281,265,249,193,73$ \\
\hline 8 & 18.5 & tetrasiloxane, decamethyl & $295,207,191,73$ \\
\hline 9 & 18.6 & silane, trimethylphenoxy- & $166,151,135,91,77$ \\
\hline 10 & 18.9 & acetophenone & $120,105,77,51$ \\
\hline 11 & 19.1 & acetic acid, [trimethylsilyl)oxy]-, trimethylsilyl ester & $205,177,147,133,73$ \\
\hline 12 & 20.1 & 2,2,3,3,7,7,8,8-octamethyl-4,6-dioxa-5-aza-2,3,7,8-tetrasilanonane & $294,206,190,73$ \\
\hline 13 & 21.5 & unknown & $293,205,146,130,73$ \\
\hline 14 & 21.8 & benzoic acid trimethylsilyl ester & $194,179,135,105,77,51$ \\
\hline 15 & 22.7 & butanedioic acid, bis(trimethylsilyl) ester & $247,172,147,73$ \\
\hline 16 & 23.4 & benzoic acid, 2-methyl-, trimethylsilyl ester & $208,193,149,119,91,65$ \\
\hline 17 & 23.7 & naphthalene, 2-ethenyl- & $154,128,76$ \\
\hline 18 & 24.4 & unknown & $442,354,266,206,146,130,73$ \\
\hline 19 & 24.5 & decanoic acid, trimethylsilyl ester & $229,145,129,117,73$ \\
\hline 20 & 24.9 & 2-propenoic acid, 3-phenyl-, trimethylsilyl ester & $220,205,161,131,103,75$ \\
\hline 21 & 25.2 & unknown & $275,147,117,73$ \\
\hline 22 & 25.6 & vinyl benzoate & $105,77,51$ \\
\hline 23 & 25.9 & benzoic acid, 3-[(trimethylsilyl)oxy]-, trimethylisilyl ester & $282,267,223,193,73$ \\
\hline
\end{tabular}




\begin{tabular}{|c|c|c|c|}
\hline 24 & 26.0 & divinyl terephthalate & $175,147,132,104,76$ \\
\hline 25 & 26.7 & unknown & $236,221,177,147,91$ \\
\hline 26 & 26.9 & 1,4-benzenedicarboxylic acid, methyl trimethylsilyl ester & $252,237,221,163,135,103$ \\
\hline 27 & 27.3 & unknown & $249,221,205,170,103$ \\
\hline 28 & 27.7 & 1,4-benzenedicarboxylic acid, ethyl trimethylsilyl ester & $251,221,207,177,149,103,76$ \\
\hline 29 & 28.1 & 1,3-benzenedicarboxylic acid, bis(trimethylsilyl) ester & $295,279,221,205,140,103,73$ \\
\hline 30 & 28.5 & 1,4-benzenedicarboxylic acid, bis(trimethylsilyl) ester & $310,295,251,221,140,103,73$ \\
\hline 31 & 29.7 & unknown & $265,221,147,103,73$ \\
\hline 32 & 30.2 & unknown & $265,249,175,149,104$ \\
\hline 33 & 30.9 & unknown & $313,295,251,221,149,117,73$ \\
\hline 34 & 31.3 & unknown & $339,221,140,103,73$ \\
\hline 35 & 32.6 & 2,2-bis[(4-trimethylsilyloxy)phenyl]propane & $372,357,207,73$ \\
\hline
\end{tabular}

\subsubsection{Polyethylene}

The DCM extracts of LDPE and HDPE - $0 w$ and $4 w$ - were analyzed. Figure 14 reports the chromatogram obtained in the Py(HMDS)-GC-MS analysis of the DCM extract of the LDPE-4w sample. The list of the main pyrolysis products is reported in Table S.6 in the Supplementary Materials.

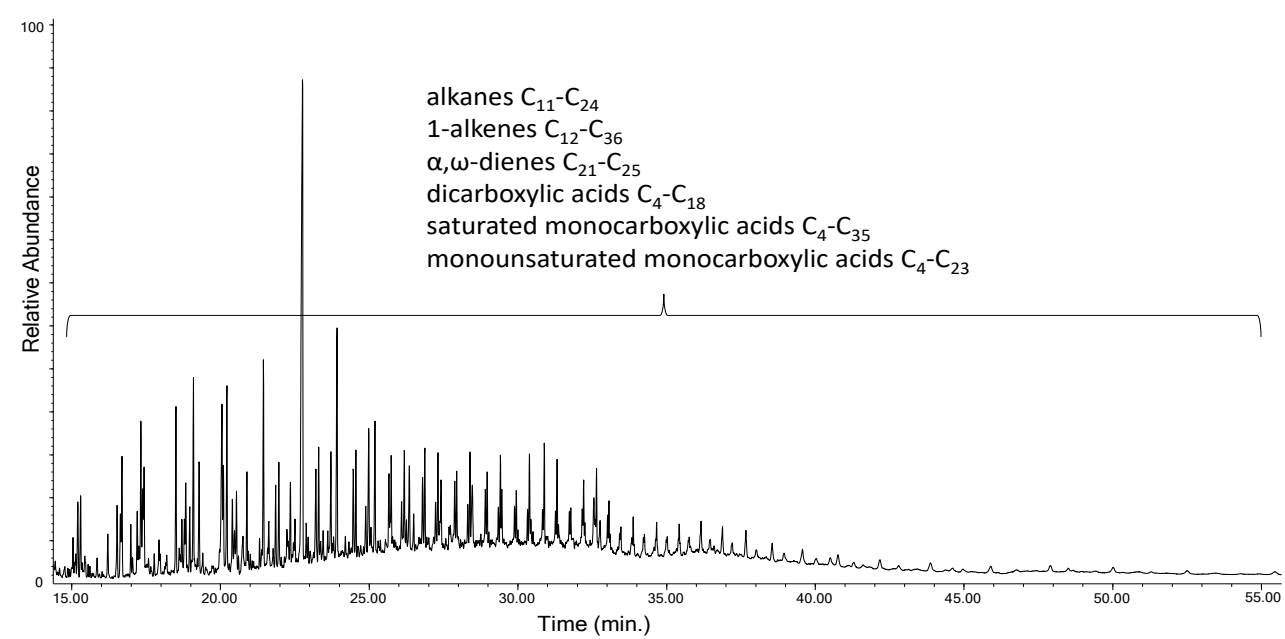

Figure 14 Chromatogram obtained in the Py(HMDS)-GC-MS analysis of the DCM extract of LDPE$4 \mathrm{w}$. The list of the main pyrolysis products is reported in Table S.6 in Supplementary Materials

Saturated monocarboxylic acids, monounsaturated monocarboxylic acids, and dicarboxylic acids are detected in the Py(HMDS)-GC-MS analysis of the extract of the aged sample, together with the pyrolysis products that were observed in the analysis of the unaged bulk (non-extracted) polymer: $\alpha, \omega$-dienes, 1-alkenes and alkanes. These oxidized products are not observed in the Py-GC-MS profile of the extract of the LDPE-0w (in Supplementary Materials, see Figure S.12 along with the list of all its main pyrolysis products in Table S.7). The complete lists of the pyrolysis products detected in the Py(HMDS)-GC-MS chromatogram of the extracts of the HDPE- $0 \mathrm{w}$ and HDPE- $4 \mathrm{w}$ are reported in the Supplementary Materials in Tables S.8 and S.9, respectively. The Py(HMDS)-GC-MS profiles of the pyrograms for the extracts of LDPE-4w and HDPE-4w show very similar general features; however, in the case of aged LDPE a higher number of oxidized pyrolysis products is observed. In particular, the analysis of the extract of the LDPE-4w highlights saturated monocarboxylic acids in the $\mathrm{C}_{4}-\mathrm{C}_{35}$ range, monounsaturated monocarboxylic acids in the 
$\mathrm{C}_{4}-\mathrm{C}_{23}$ range, and dicarboxylic acids in the $\mathrm{C}_{4}-\mathrm{C}_{18}$ range. For the extract of the HDPE- $4 \mathrm{w}$ sample, saturated monocarboxylic acids in the Py-GC-MS chromatograms are in the $\mathrm{C}_{5}$ $\mathrm{C}_{20}$ range, monounsaturated monocarboxylic acids in the $\mathrm{C}_{4}-\mathrm{C}_{18}$ range, and dicarboxylic acids in the $\mathrm{C}_{4}-\mathrm{C}_{12}$ range (Table S.9). Even in this case a recurrent pyrolysis pattern can be highlighted (Figure 15): along with the formation of the $\alpha, \omega$-diene and 1-alkene, we observe the presence of the dicarboxylic acid (Cn-9), the monounsaturated monocarboxylic acid $\left(C_{n-4}\right)$ and the monocarboxylic acid $\left(C_{n}-4\right)$ of a given hydrocarbon $\left(C_{n}\right)$.

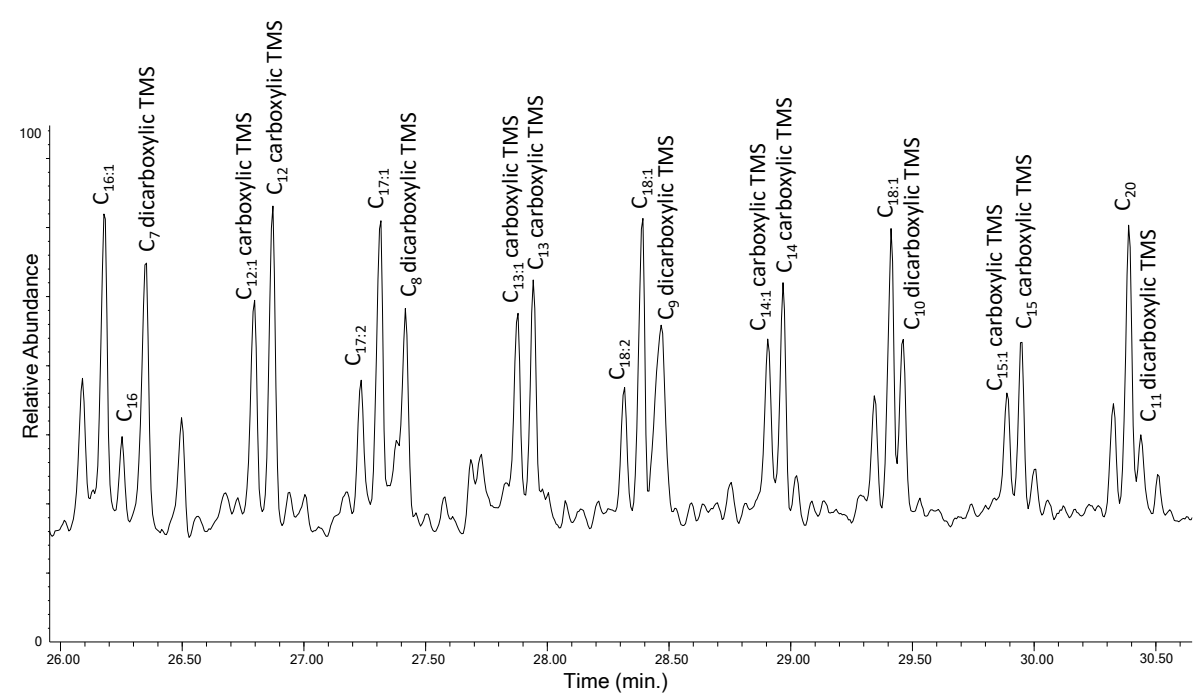

Figure 15 Chromatogram obtained (26.00-30.50 $\mathrm{min}$ ) in the Py(HMDS)-GC-MS analysis of the DCM extract of LDPE-4w. Cn:2 refers to $\alpha, \omega$-dienes, $\mathrm{Cn}: 1$ to 1 -alkenes, and $\mathrm{Cn}$ to alkanes of a given $\mathrm{Cn}$ hydrocarbon.

a)

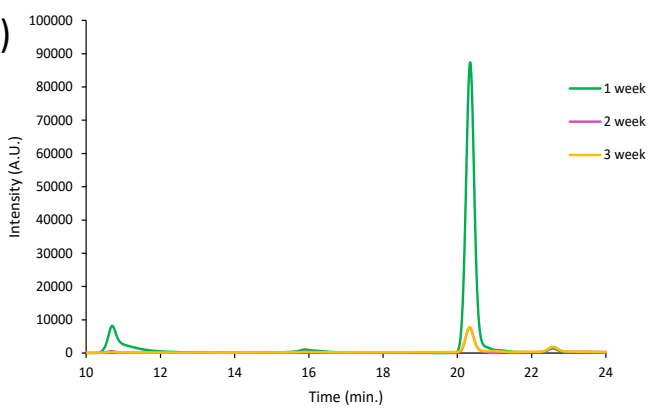

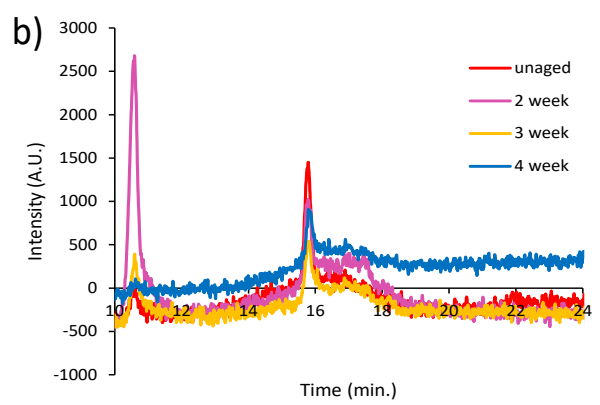

Figure 16 SEC chromatograms (10-24 min) of the DCM extracts of HDPE- $0 w$ (red), HDPE- $1 \mathrm{w}$ (green), HDPE-2w (purple), HDPE-3w (yellow), and HDPE-4w (blue) acquired with a RI detector (a) and at $260 \mathrm{~nm}$ (b).

Figures 16.a and 16.b show the SEC chromatograms (10-24 min.) of the DCM extracts of HDPE-0w (red), HDPE-1w (green), HDPE-2w (purple), HDPE-3w (yellow), and HDPE$4 \mathrm{w}$ (blue) acquired with a RI detector and at $260 \mathrm{~nm}$, respectively. The SEC chromatograms acquired with a RI detector of the HDPE samples show two peaks at around 20 and 22 minutes corresponding to the low molecular weight fractions that are expected, as for $\mathrm{PP}$, due to the fact that the high molecular weight polyolefins are insoluble in DCM. All the extracts show two signals in the $260 \mathrm{~nm}$ chromatographic profiles that are not observed in the chromatograms acquired at $340 \mathrm{~nm}$ : the first one at about 10 minutes, corresponding to the one found in the RI chromatograms, and a second one at about 16 minutes characterized by low intensity that has no corresponding peak in the RI chromatogram, which suggests the presence of impurities. As for LDPE, the SEC-RI chromatograms are 
completely identical to the ones of the HDPE extracts, while the $260 \mathrm{~nm}$ SEC-UV chromatographic profiles do not show any peak.

\subsection{Analysis of insoluble fractions of reference polymers before and after artificial aging}

The insoluble residues from the DCM (MeOH for PS) extractions were analyzed by means of Py-GC-MS to complement the analysis of the aged polymers and of the extracts, and to evaluate the effectiveness of the extraction procedure.

\subsubsection{Polypropylene}

The chromatograms obtained in the Py-GC-MS analysis of the extraction residues (DCM insoluble fraction) of PP- $0 \mathrm{w}$ (red) and PP-4w (blue) are reported in Figure 17. The list of the pyrolysis products identified in both the chromatograms is in Table S.10 in the Supplementary Materials. The two pyrolytic profiles do not show significant differences, and both feature the usual fragmentation pattern produced in the pyrolysis of $\mathrm{PP}$, indicating that the DCM extraction has proven to be very effective. The extractable fraction of PP is observed to increase with aging: for the unaged PP- $0 \mathrm{w}$, the extractable fraction is the $0.6 \%$ of the sample, while for PP- $4 \mathrm{w}$, it reaches $16.3 \%$. PP oligomers with chain length up to C40 are detected in the Py-GC-MS analysis of the extracts, whereas in the pyrolytic profiles of the bulk (non-extracted) PP samples only PP oligomers up to C34 were detected. As for $\mathrm{PP}$, the usefulness of the extraction procedure is demonstrated by the fact that the oxidized fraction, that cannot be detected in the pyrogram of the aged bulk sample, is detected in the pyrogram of the corresponding extract, allowing the identification of higher molecular weight PP oligomers in the pyrogram of the corresponding extract residue.

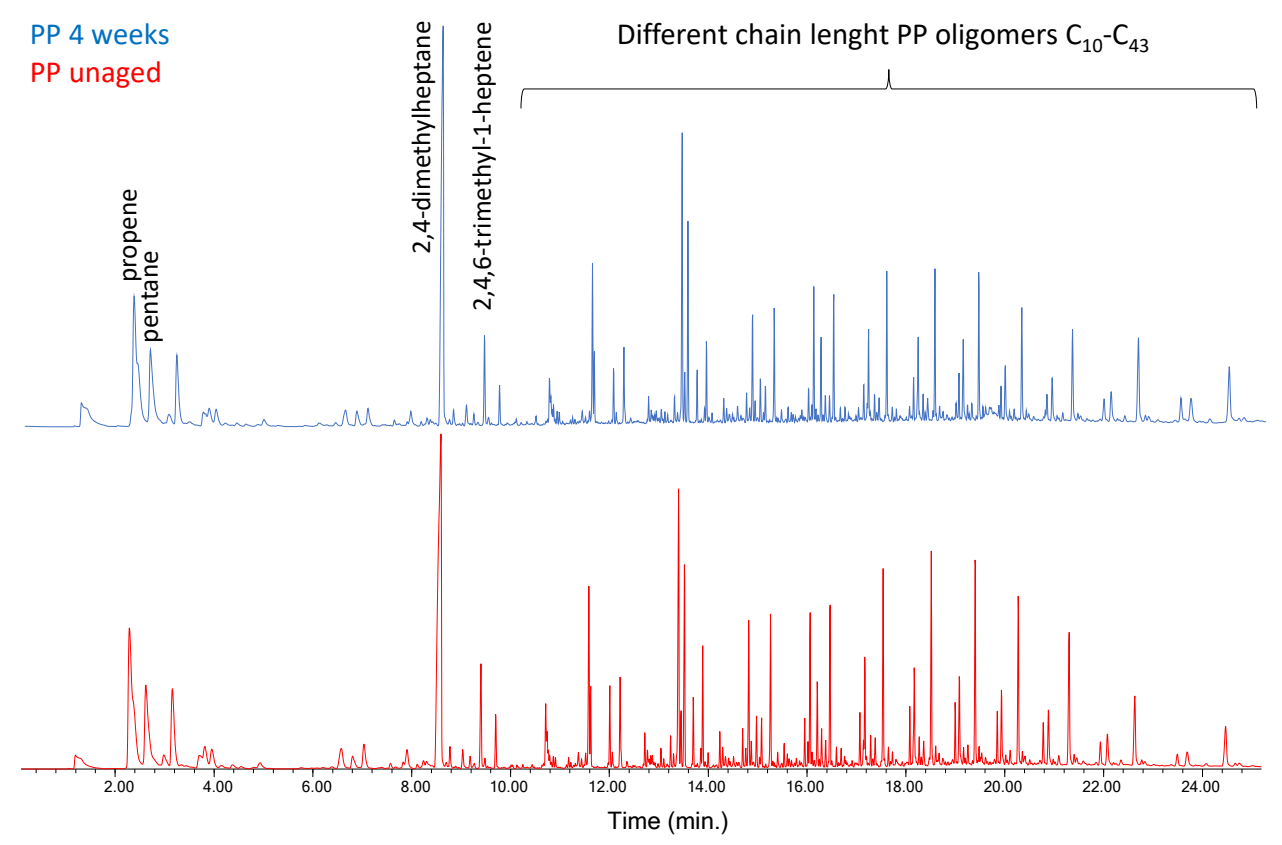

Figure 17 Chromatograms obtained in the Py-GC-MS analysis of the extraction residues of PP-0w (red) and PP-4w (blue). The complete list of the main pyrolysis products is reported in Table S.10 in the Supplementary Materials.

\subsubsection{Polystyrene}

The chromatograms obtained in the Py-GC-MS analysis of the extraction residues $(\mathrm{MeOH}$ insoluble fraction) of PS-0w (red) and PS-4w (blue) are reported in Figure 18. The complete 
list of the pyrolysis products identified in both chromatograms in Table S.11 in the Supplementary Materials. The pyrolytic profiles of the extraction residues of the unaged PS$0 \mathrm{w}$ and aged PS- $4 \mathrm{w}$ samples are very similar, showing mainly the pyrolysis products of reference unaged PS: toluene, styrene and its dimer and trimer. By comparing the two profiles, the only difference is the lower relative abundance of the styrene dimer and styrene trimer in the profile of the aged PS- $4 \mathrm{w}$. It is to be underlined that after $\mathrm{MeOH}$ extraction, the insoluble residue of the yellowed PS- $4 \mathrm{w}$ appears white, indicating that all the colored products that were formed during artificial aging were efficiently extracted in $\mathrm{MeOH}$.

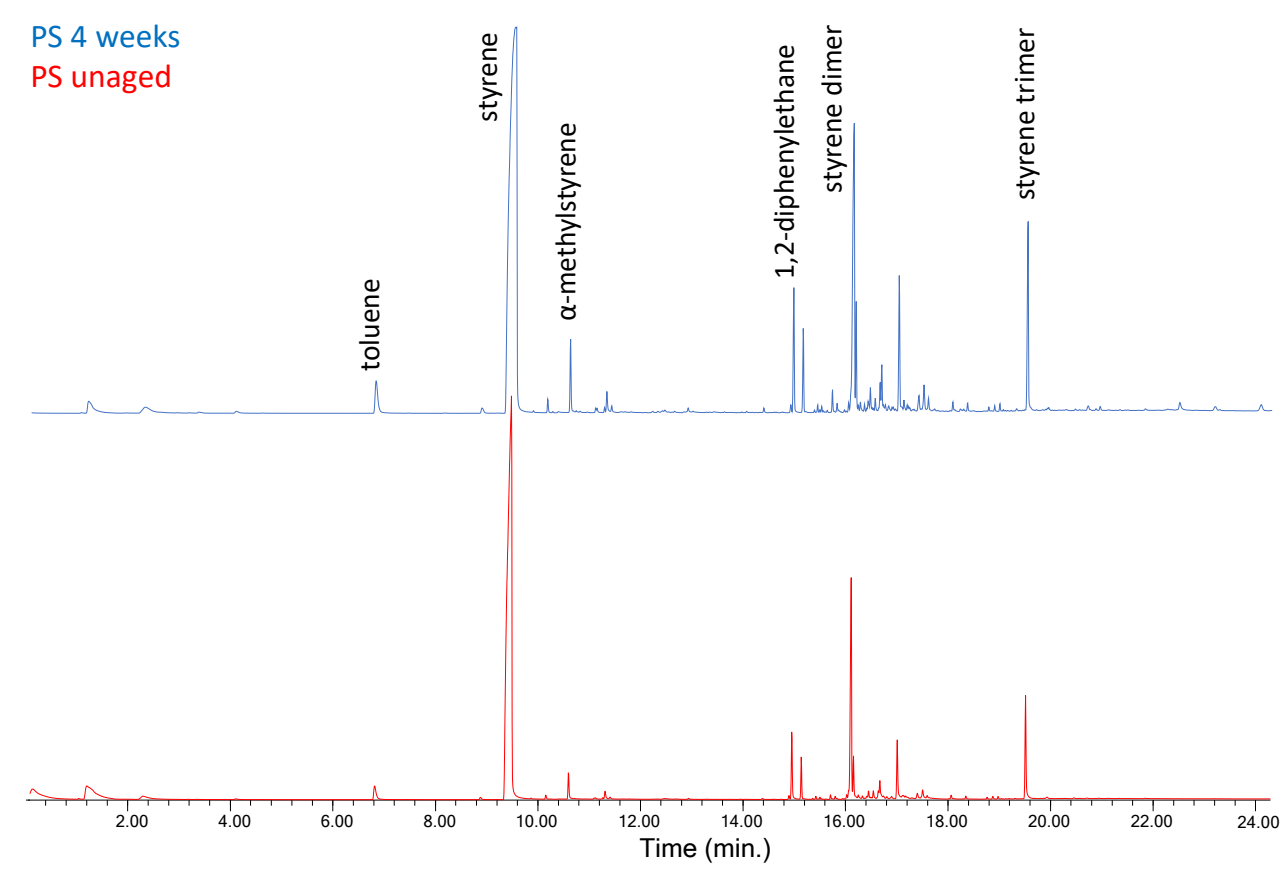

Figure 18 Chromatograms obtained in the Py-GC-MS analysis of the extraction residues of PS-0w (red) and PS-4w (blue). The complete list of the main pyrolysis products is reported in Table S.11 in Supplementary Materials.

\subsubsection{Polyethylene terephthalate}

The Py-GC-MS profiles of the extraction residues (DCM insoluble fraction) of PET- $0 \mathrm{w}$ and PET-4w resulted completely undistinguishable, as observed also for the DCM extracts. They are also very similar to the pyrograms of the corresponding bulk (non-extracted) samples featuring benzene, vinyl benzoate, benzoic acid, biphenyl, divinyl terephthalate and ethan-1,2-diyldibenzoate. As expected, PET appears not to be affected by photo-oxidation in the adopted conditions. Figure S.13 in the Supplementary Materials reports the chromatograms obtained in the Py-GC-MS analysis of the extraction residues of the PET0w (red) and PET- $4 \mathrm{w}$ (blue). The complete list of the pyrolysis products identified in both chromatograms is reported in Table S.12 in the Supplementary Materials.

\subsubsection{Polyethylene}

The pyrolysis profile of the extraction residues (DCM insoluble fraction) of LDPE, both unaged $0 \mathrm{w}$ and aged $4 \mathrm{w}$, are very similar to the ones of the corresponding profiles for HDPE. Therefore, only LDPE is discussed here. Figure 19 reports the chromatograms obtained in the Py-GC-MS analysis of the extraction residues of the LDPE- $0 \mathrm{w}$ (red) and LDPE-4w (blue). The complete list of the pyrolysis products identified in both the chromatograms is reported in Table S.13 in the Supplementary Materials. The pyrogram of the extraction residue of LDPE- $4 \mathrm{w}$ does not show the presence of any of the oxidized products (saturated aldehydes, monocarboxylic acids, alcohols, and ketones) that were observed in 
the analysis of the extract. The DCM extraction step has proven to be very effective in the extraction of HDPE- $4 w$ and LDPE- $4 w$ samples, just as observed for the PP- $4 w$ and PS- $4 w$ samples. The extractable fraction increases with aging for both LDPE (from $2.1 \%$ for LDPE- $0 w$ to $11.3 \%$ for LDPE- $4 w$ ) and HDPE (from $0.6 \%$ for HDPE- $0 \mathrm{w}$ to $2.6 \%$ for HDPE$4 \mathrm{w})$. Moreover, even in this case, in the pyrograms of the insoluble residues of both samples, PE oligomers are observed to present higher molecular weight (up to $\mathrm{C}_{33}$ ) than in the pyrograms of the corresponding bulk samples (molecular weight up to $\mathrm{C}_{26}$ ).

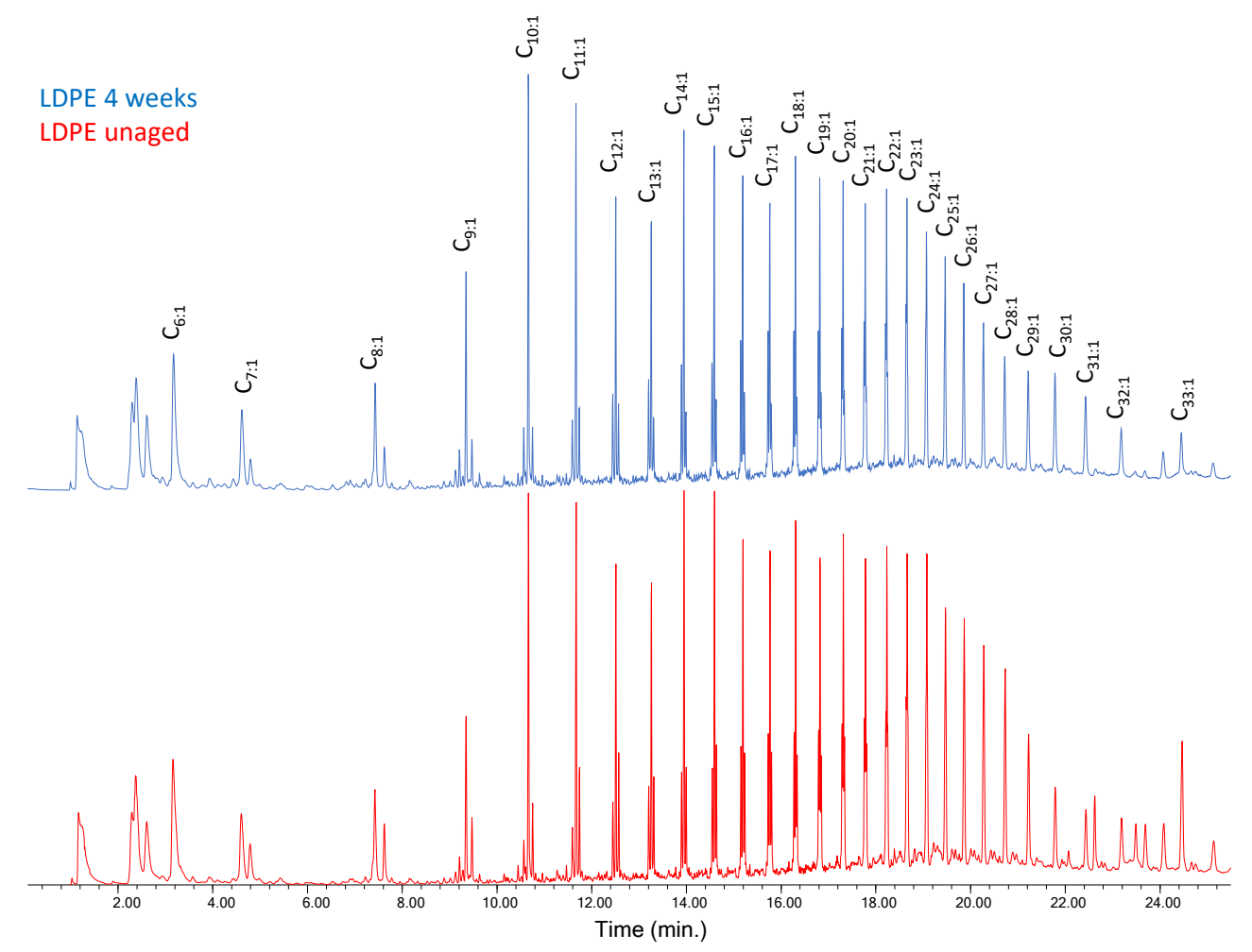

Figure 19 Chromatograms obtained in the Py-GC-MS analysis of the extraction residues of the LDPE-0w (red) LDPE-4w (blue) The complete list of the main pyrolysis products is reported in Table S.13 in the Supplementary Materials.

\section{Conclusions}

EGA-MS, Py-GC-MS, and SEC were applied for the first time to fully characterize reference polymers in the form of microplastic sand to investigate the effects of artificial photoaging on micropowders of LDPE, HDPE, PP, PS, and PET and to gain insights on the nature of the degradation products that may be relevant to a better understanding of the fate and toxicity potential of microplastics released or generated in the environment from dispersed plastic waste. To characterize with optimized sensitivity the degraded/oxidized fraction, all the polymers - unaged and aged up to 4 weeks in a solarbox - were fractionated by extraction with refluxing dichloromethane or, in the case of PS, with methanol, that is, with non-solvents for the undegraded polymers but good solvents for the most highly oxidized and/or low molecular weight/oligomeric fractions generated by the photo-oxidation processes. Both the bulk polymers (that is, the polymer micropowders before fractionation by solvent extraction, irrespective of aging) and the fractions obtained upon solvent extraction (solvent extracts and the insoluble residues) were then further analyzed and compared.The EGA-MS analyses on bulk polymers allowed to assess the changes in the thermal degradation behavior induced by photo-oxidative degradation, while the Py-GC-MS analyses provided additional information on the degradation products formed during induced aging, in particular in the case of HDPE and LDPE for which carboxylic acids, aldehydes, ketones and alcohols were detected. However, because of their low concentration, volatility and high polarity, the efficient characterization of these 
photo-oxidative degradation products required the use of hexamethyldisilazane (HMDS) as a derivatization agent. Indeed, the Py(HMDS)-GC-MS analysis of the extractable fractions showed the presence of monocarboxylic and dicarboxylic acids in the chromatograms of all of the 4 weeks aged polymers; these soluble fractions were also be analyzed by SEC to achieve a more complete characterization of the correlation between the extent of oxidation and the reduction of molecular weight as a result of the photo-oxidative degradation.

The analyses allowed us to observe the following behaviors and phenomena:

- the well-known photo-oxidative degradation and chain fragmentation behavior of PP was associated, in the EGA-MS thermograms, with a progressive decrease of thermal degradation temperature along with peak broadening with aging; moreover, Py (HMDS)-GC-MS analysis of the DCM extracts highlighted the presence of low molecular weight mono, dicarboxylic acids, and hydroxy acids in the aged sample;

- as expected, both LDPE and, particularly, HDPE underwent less extensive photooxidative degradation and fragmentation when compared to PP, as highlighted by the pyrolysis profile of the unaged and aged bulk polymers; in addition, the pyrolysis profile of the polyethylenes- $4 \mathrm{w}$ featured aldehydes, ketones, alcohols and monocarboxylic acids, that were all the more present, along with other oxidation products, in the Py(HMDS)-GC-MS profile of the respective DCM-extractable fraction after 4 weeks aging;

- photo-aging of PS induces both chain scission and crosslinking reactions, as highlighted by the presence of oxidized compounds (monocarboxylic and dicarboxylic acids, along with acids and alcohols deriving from benzoic acid) in the Py (HMDS)-GC-MS analysis of the extract of the 4 weeks aged PS; on the other hand, the concomitant occurrence of cross-linking reactions was highlighted by SEC;

- the expected comparatively higher photo-oxidative stability of PET was confirmed by the lack of significant changes in the pyrograms upon artificially aging. Finally, the Py-GC-MS analysis of the insoluble residues of the extraction highlighted the effectiveness of the extraction procedure in separating low molecular weight degradation products: the pyrolytic profile obtained for the insoluble residue (that is, nearly $100 \%$ of it) of each unaged polymer was nearly identical to the one obtained for the insoluble residue of the corresponding 4 weeks aged polymer. The results obtained in this systematic analysis of photo-oxidative degradation of reference polymers pave the ground for a more detailed characterization of the oxidation products that may leach out from plastic debris dispersed in the environment, and then to an extension of this study aimed at investigating the possible connections between the pollution by microplastics and the toxicity potential of the low molecular weight, oxidized species that may leach out of MPs in natural sea- and freshwaters, soils, and in other environmental compartments.

Supplementary Materials: The following are available online at www.mdpi.com/xxx/s1, Figures S.1-S.16; Tables S.1-S.13

Author Contributions: Conceptualization, A.C. V.C., Methodology and formal analysis, G.B., J.L.N, A.C., V.V.; all the authors participated in the investigation; all the authors participated in the writing - review and editing of the manuscript; visualization, J.L.N., A.C., V.V., V.C., F.M; supervision, V.C, F.M.; project administration, V.C, F.M.; funding acquisition, V.C, F.M.; all authors have read and agreed to the published version of the manuscript.".

Funding: Funding for the fellowship of V.V. came from Fondazione Cassa di Risparmio di Lucca (Bando Ricerca 2019-21, CISUP project "Micro- e nano-plastiche: metodologie di quantificazione, valutazione dell'impatto in ecosistemi marini e lacustri, strategie di remediation ambientale"). Additional funding from the University of Pisa, PRA project 2020_27 on Micro- and nanoplastics, is also gratefully acknowledged.

Conflicts of Interest: The authors declare no conflict of interest. 


\section{References}

1. 1. Andrady, A.L. Microplastics in the marine environment. Marine Pollution Bulletin 2011, 62, 1596-1605, doi:https://doi.org/10.1016/j.marpolbul.2011.05.030.

2. 2. Betts, K. Why small plastic particles may pose a big problem in the oceans. Environmental Science \& Technology 2008, 42, 8995-8995, doi:10.1021/es802970v.

3. 3. Browne, M.A.; Crump, P.; Niven, S.J.; Teuten, E.; Tonkin, A.; Galloway, T.; Thompson, R. Accumulation of microplastic on shorelines woldwide: sources and sinks. Environmental Science \& Technology 2011, 45, 9175-9179.

4. 4. Frere, L.; Paul-Pont, I.; Rinnert, E.; Petton, S.; Jaffré, J.; Bihannic, I.; Soudant, P.; Lambert, C.; Huvet, A. Influence of environmental and anthropogenic factors on the composition, concentration and spatial distribution of microplastics: a case study of the Bay of Brest (Brittany, France). Environmental Pollution 2017, 225, 211-222.

5. $\quad 5 . \quad J a m b e c k$, J.R.; Geyer, R.; Wilcox, C.; Siegler, T.R.; Perryman, M.; Andrady, A.; Narayan, R.; Law, K.L. Plastic waste inputs from land into the ocean. Science 2015, 347, 768, doi:10.1126/science.1260352.

6. 6. Shahul Hamid, F.; Bhatti, M.S.; Anuar, N.; Anuar, N.; Mohan, P.; Periathamby, A. Worldwide distribution and abundance of microplastic: How dire is the situation? Waste Management \& Research 2018, 36, 873-897, doi:10.1177/0734242X18785730.

7. 7. Horton, A.A.; Walton, A.; Spurgeon, D.J.; Lahive, E.; Svendsen, K. Microplastics in freshwater and terrestrial environments: Evaluating the current understanding to identify the knowledge gaps and future research priorities. Science of the Total Environment 2017, 586, 127-141.

8. 8. Frias, J.; Nash, R. Microplastics: finding a consensus on the definition. Marine pollution bulletin 2019, 138, 145-147.

9. 9. Fendall, L.S.; Sewell, M.A. Contributing to marine pollution by washing your face: Microplastics in facial cleansers. Marine Pollution Bulletin 2009, 58, 1225-1228, doi:https://doi.org/10.1016/j.marpolbul.2009.04.025.

10. 10. Gewert, B.; Plassmann, M.; Sandblom, O.; MacLeod, M. Identification of Chain Scission Products Released to Water by Plastic Exposed to Ultraviolet Light. Environmental Science \& Technology Letters 2018, 5, 272-276, doi:10.1021/acs.estlett.8b00119.

11. 11. Ceccarini, A.; Corti, A.; Erba, F.; Modugno, F.; La Nasa, J.; Bianchi, S.; Castelvetro, V. The Hidden Microplastics: New Insights and Figures from the Thorough Separation and Characterization of Microplastics and of Their Degradation Byproducts in Coastal Sediments. Environmental Science \& Technology 2018, 52, 5634-5643, doi:10.1021/acs.est.8b01487.

12. 12. Bejgarn, S.; MacLeod, M.; Bogdal, C.; Breitholtz, M. Toxicity of leachate from weathering plastics: An exploratory screening study with Nitocra spinipes. Chemosphere 2015, 132, 114-119, doi:https://doi.org/10.1016/j.chemosphere.2015.03.010.

13. 13. La Nasa, J.; Lomonaco, T.; Manco, E.; Ceccarini, A.; Fuoco, R.; Corti, A.; Modugno, F.; Castelvetro, V.; Degano, I. Plastic breeze: Volatile organic compounds (VOCs) emitted by degrading macro- and microplastics analyzed by selected ion flow-tube mass spectrometry. Chemosphere 2021, 270, 128612, doi:https://doi.org/10.1016/j.chemosphere.2020.128612.

14. 14. Schwaferts, C.; Niessner, R.; Elsner, M.; Ivleva, N.P. Methods for the analysis of submicrometer- and nanoplastic particles in the environment. TrAC Trends in Analytical Chemistry 2019, 112, 52-65, doi:https://doi.org/10.1016/j.trac.2018.12.014.

15. 15. Zhang, S.; Wang, J.; Liu, X.; Qu, F.; Wang, X.; Wang, X.; Li, Y.; Sun, Y. Microplastics in the environment: A review of analytical methods, distribution, and biological effects. TrAC Trends in Analytical Chemistry 2019, 111, 62-72, doi:https://doi.org/10.1016/j.trac.2018.12.002.

16. 16. Dümichen, E.; Eisentraut, P.; Bannick, C.G.; Barthel, A.-K.; Senz, R.; Braun, U. Fast identification of microplastics in complex environmental samples by a thermal degradation method. Chemosphere 2017, 174, 572-584, doi:https://doi.org/10.1016/j.chemosphere.2017.02.010.

17. 17. David, J.; Weissmannová, H.D.; Steinmetz, Z.; Kabelíková, L.; Demyan, M.S.; Šimečková, J.; Tokarski, D.; Siewert, C.; Schaumann, G.E.; Kučerík, J. Introducing a soil universal model method (SUMM) and its application for qualitative and quantitative determination of poly (ethylene), poly (styrene), poly (vinyl chloride) and poly (ethylene terephthalate) microplastics in a model soil. Chemosphere 2019, 225, 810-819.

18. 18. David, J.; Steinmetz, Z.; Kučerík, J.; Schaumann, G.E. Quantitative Analysis of Poly(ethylene terephthalate) Microplastics in Soil via Thermogravimetry-Mass Spectrometry. Analytical Chemistry 2018, 90, 8793-8799, doi:10.1021/acs.analchem.8b00355.

19. 19. Primpke, S.; Fischer, M.; Lorenz, C.; Gerdts, G.; Scholz-Böttcher, B.M. Comparison of pyrolysis gas chromatography/mass spectrometry and hyperspectral FTIR imaging spectroscopy for the analysis of microplastics. Analytical and Bioanalytical Chemistry 2020, 412, 8283-8298, doi:10.1007/s00216-020-02979-w.

20. 20. Tsuge, S.; Ohtani, H.; Watanabe, C. Pyrolysis-GC/MS data book of synthetic polymers: pyrograms, thermograms and MS of pyrolyzates; Elsevier: 2011.

21. 21. Moldoveanu, S.C. Analytical pyrolysis of synthetic organic polymers; Elsevier: 2005.

22. 22. La Nasa, J.; Biale, G.; Fabbri, D.; Modugno, F. A review on challenges and developments of analytical pyrolysis and other thermoanalytical techniques for the quali-quantitative determination of microplastics. Journal of Analytical and Applied Pyrolysis 2020, 149, 104841, doi:https://doi.org/10.1016/j.jaap.2020.104841.

23. 23. Lomonaco, T.; Manco, E.; Corti, A.; La Nasa, J.; Ghimenti, S.; Biagini, D.; di Francesco, F.; Modugno, F.; Ceccarini, A.; Castelvetro, V.; et al. Release of harmful volatile organic compounds (VOCs) from photo-degraded plastic debris: a neglected 
source of environmental pollution. Journal of Hazardous Materials 2020, 394, 122596, doi:https://doi.org/10.1016/j.jhazmat.2020.122596.

24. 24. Manco, E. Studio della correlazione tra le caratteristiche strutturali e i composti organici volatili emessi da polimeri di sintesi a seguito di processi di invecchiamento foto- e termoossidativo. University of Pisa, 2019.

25. 25. La Nasa, J.; Biale, G.; Mattonai, M.; Modugno, F. Microwave-assisted solvent extraction and double-shot analytical pyrolysis for the quali-quantitation of plasticizers and microplastics in beach sand samples. Journal of Hazardous Materials 2021, 401, 123287, doi:https://doi.org/10.1016/j.jhazmat.2020.123287.

26. 26. La Nasa, J.; Biale, G.; Ferriani, B.; Trevisan, R.; Colombini, M.P.; Modugno, F. Plastics in Heritage Science: Analytical Pyrolysis Techniques Applied to Objects of Design. Molecules 2020, 25, doi:10.3390/molecules25071705.

27. 27. Castelvetro, V.; Corti, A.; La Nasa, J.; Modugno, F.; Ceccarini, A.; Giannarelli, S.; Vinciguerra, V.; Bertoldo, M. Polymer Identification and Specific Analysis (PISA) of Microplastic Total Mass in Sediments of the Protected Marine Area of the Meloria Shoals. Polymers 2021, 13, doi:10.3390/polym13050796.

28. 28. Gewert, B.; Plassmann, M.M.; MacLeod, M. Pathways for degradation of plastic polymers floating in the marine environment. Environmental Science Processes and Impacts 2015, 17, 1513.

29. 29. Chiellini, E.; Corti, A.; D'Antone, S.; Baciu, R. Oxo-biodegradable carbon backbone polymers - Oxidative degradation of polyethylene under accelerated test conditions. Polymer Degradation and Stability 2006, 91, 2739-2747.

30. 30. Luda, M.P.; Dall'Anese, R. On the microstructure of polypropylenes by pyrolysis GC-MS. Polymer Degradation and Stability 2014, 110, 35-43.

31. 31. Bottino, F.A.; Cinquegrani, A.R.; Di Pasquale, G.; Leonardi, L.; Pollicino, A. Chemical modifications, mechanical properties and surface photo-oxidation of films of polystyrene (PS). Polymer Testing 2004, 23, 405-411.

32. 32. Castelvetro, V.; Corti, A.; Bianchi, S.; Ceccarini, A.; Manariti, A.; Vinciguerra, V. Quantification of poly(ethylene terephthalate) micro- and nanoparticle contaminants in marine sediments and other environmental matrices. Journal of Hazardous Materials 2020, 385, 121517.

33. 33. Castelvetro, V.; Corti, A.; Biale, G.; Ceccarini, A.; Degano, I.; La Nasa, J.; Lomonaco, T.; Manariti, A.; Manco, E.; Modugno, F.; et al. New methodologies for the detection, identification, and quantification of microplastics and their environmental degradation by-products. Environmental Science and Pollution Research 2021, doi:10.1007/s11356-021-12466-z. 